\title{
Keck Planet Finder: Zerodur optical bench mechanical design
}

Christopher Smith, Steven R. Gibson, Andrew W. Howard, Jerry Edelstein, Edward H. Wishnow, et al.

Christopher Smith, Steven R. Gibson, Andrew W. Howard, Jerry Edelstein, Edward H. Wishnow, Kodi Rider, "Keck Planet Finder: Zerodur optical bench mechanical design," Proc. SPIE 10702, Ground-based and Airborne Instrumentation for Astronomy VII, 107026Y (9 July 2018); doi: 10.1117/12.2313969

Event: SPIE Astronomical Telescopes + Instrumentation, 2018, Austin, Texas, United States 


\title{
Keck Planet Finder: Zerodur Optical Bench Mechanical Design
}

\author{
Christopher Smith ${ }^{\mathrm{a}}$, Steven R. Gibson ${ }^{\mathrm{a}}$, Andrew W. Howard ${ }^{\mathrm{b}, \mathrm{a}}$, Jerry Edelstein ${ }^{\mathrm{a}}$, Edward H. \\ Wishnow $^{\mathrm{a}}$, and Kodi Rider ${ }^{\mathrm{a}}$ \\ aSpace Sciences Laboratory, University of California, Berkeley, United States \\ ${ }^{\mathrm{b}}$ California Institute of Technology, Pasadena, United States
}

\begin{abstract}
The Keck Planet Finder (KPF) is a fiber-fed, high-resolution, high-stability spectrometer in development for the W.M. Keck Observatory. To measure Doppler shifts to $0.5 \mathrm{~m} / \mathrm{s}$ or better requires some of the optics be stable to $2 \mathrm{~nm}$ vertically and $2 \mathrm{nrad}$ in pitch angle throughout a potentially one hour long observation. One traditional approach to this thermal stability problem is to build a metal bench and then control the spectrometer thermal environment to milli-Kelvin levels. An alternative approach used by KPF is to employ a Zerodur bench of extremely low coefficient of expansion (CTE), which relaxes the thermal stability required for the spectrometer assembly. Furthermore, Zerodur optics with integral mounts are used where possible, and are placed in contact with the bench through Zerodur shims. Springs are used to preload the optics and shims within pockets machined into the Zerodur bench. We will describe how this approach has been adapted for each optic (some of which are $450 \mathrm{~mm}$ high with a mass of $30 \mathrm{~kg}$ ), and how the system meets our earthquake survival requirement of $0.92 \mathrm{~g}$. This mounting scheme allows us to avoid using high-CTE metals or adhesives within the optic mounting system, and therefore fully exploit the high thermal stability of the Zerodur optical bench.
\end{abstract}

Keywords: Spectrometer, Exoplanets, Doppler Spectroscopy, Zerodur, Optical Bench

\section{INTRODUCTION}

The Keck Planet Finder (KPF) is a fiber-fed, high-resolution, high-stability spectrometer being developed for the W.M. Keck Observatory (WMKO). ${ }^{1}$ The instrument is designed to characterize exoplanets via Doppler spectroscopy with a single measurement precision of $0.5 \mathrm{~m} / \mathrm{s}$ or better; however, its resolution and stability will enable a wide variety of other astrophysical pursuits. The project is now in the detailed design phase, having passed the Preliminary Design Review (PDR) in November 2017. First light is expected in late 2020.

Several institutions are involved in the KPF project: SSL at UC Berkeley is the primary design and build location; WMKO is responsible for the fiber injection unit, facility modifications, and instrument software; University of California Observatories (UCO) is working on the detectors and the instrument software; the California Institute of Technology (Caltech) is developing the data reduction pipeline and is also involved with the design and testing of the detectors; and Macquarie University is developing the Fabry-Perot etalon for the KPF calibration system.

\section{SPECTROMETER OPTICAL BENCH OVERVIEW}

The KPF spectrometer will be located within the Keck Observatory basement, as close to the Keck I telescope as possible. It will sit inside a vacuum chamber which is, in turn, inside a thermal enclosure (Figure 1). The optical bench is a 2 meter diameter, $122 \mathrm{~mm}$ thick disk of Zerodur. This disk is mounted in the vacuum chamber on five Minus-K CM-1 vibration isolators. The majority of the optical elements for the spectrometer are also made of Zerodur; they contact the bench through Zerodur shims and are held in place by spring mechanisms (Figure 2). With this approach nothing but Zerodur controls the position of our most position-sensitive optics, allowing for very low thermal sensitivity for the spectrometer.

\footnotetext{
Corresponding author email: csmith@ssl.berkeley.edu
}

Ground-based and Airborne Instrumentation for Astronomy VII, edited by Christopher J. Evans, Luc Simard, Hideki Takami, Proc. of SPIE Vol. 10702, 107026Y · C 2018 SPIE · CCC code: 0277-786X/18/\$18 · doi: 10.1117/12.2313969 


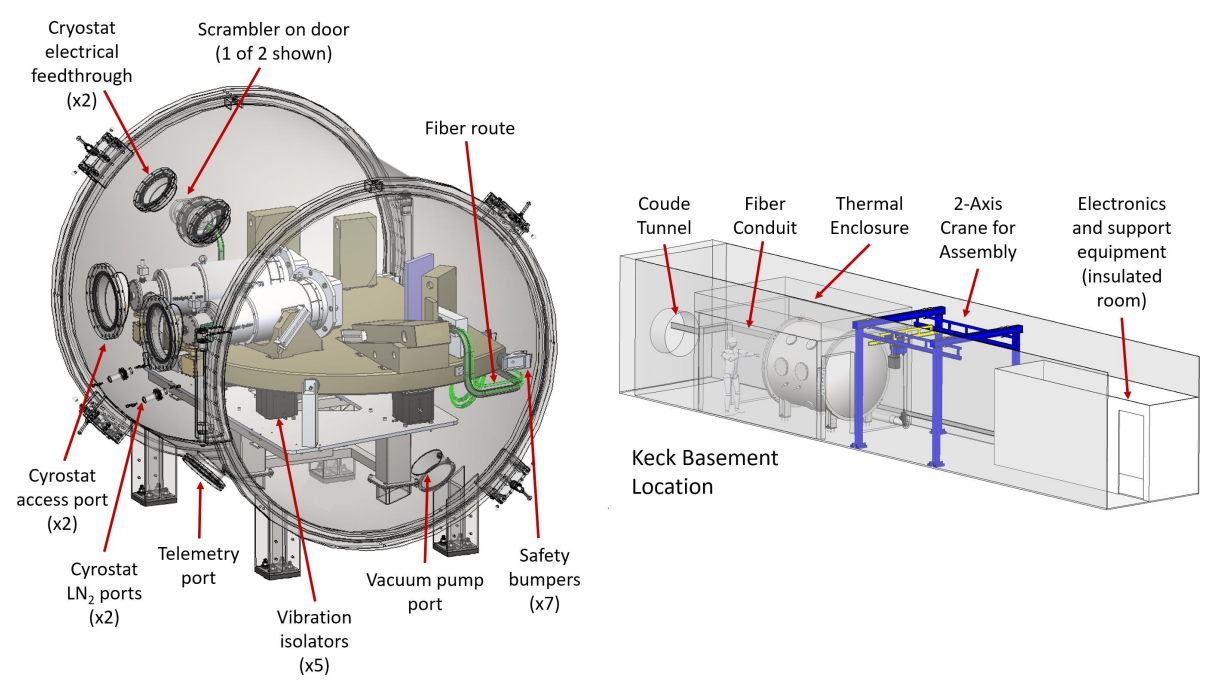

Figure 1. The KPF vacuum chamber and Keck basement location.

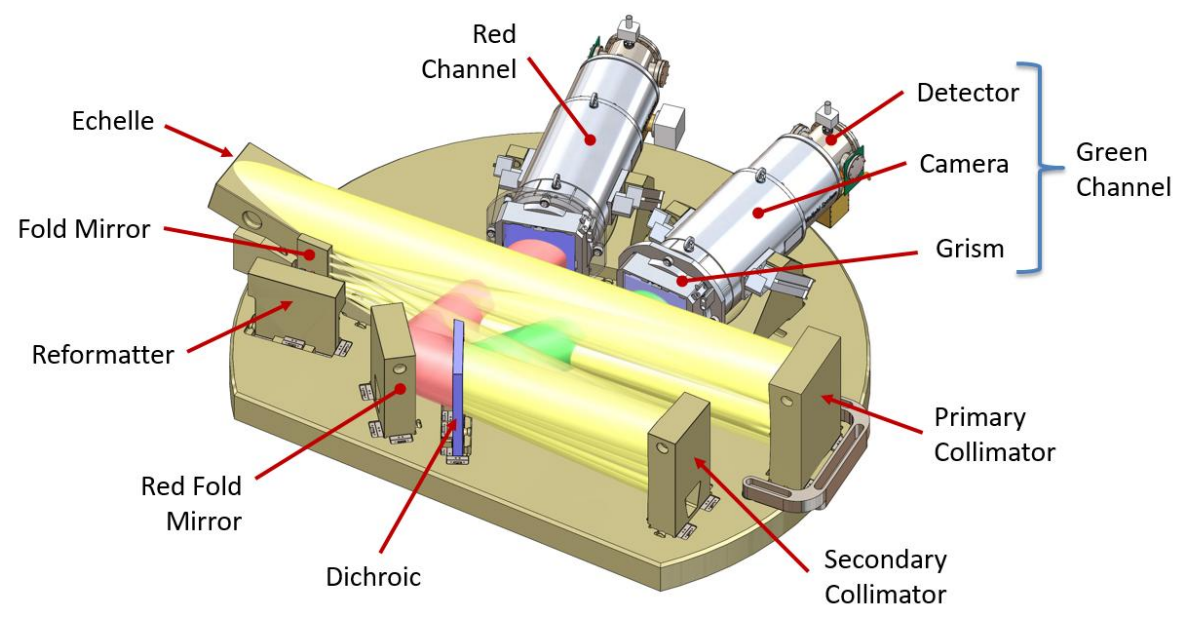

Figure 2. The KPF opto-mechanical design, with the optical elements supported by a Zerodur bench.

\section{SPECTROMETER OPTICAL BENCH ALIGNMENT AND STABILITY REQUIREMENTS}

There are two broad tolerance categories for the KPF spectrometer, alignment and stability, and it is important to distinguish between them. The alignment tolerances address how accurately the optical elements need to be positioned on the optical bench to ensure that a spectrum of acceptable image quality is placed on the detector. The stability tolerances address how stable an optic needs to remain throughout an hour-long observation. The stability tolerances are orders of magnitude smaller than the alignment tolerances. More details on the tolerancing studies are available in Gibson $(2016) .^{2}$

\subsection{Alignment Tolerances}

The alignment tolerance analysis was based on image quality (spot size) and the position of the spectrum on the CCD. From an overall spot size requirement of less than 20 microns RMS (radius), 12 microns RMS radius was apportioned to the alignment tolerances. As well, the position of the spectrum on the detector must not move by more than 50 pixels away from its nominal position given the sum of all DOF perturbations. Given these two metrics, some of the tolerance values presented below were driven by spot sizes, and some were driven by position of the spectrum on the detector. 

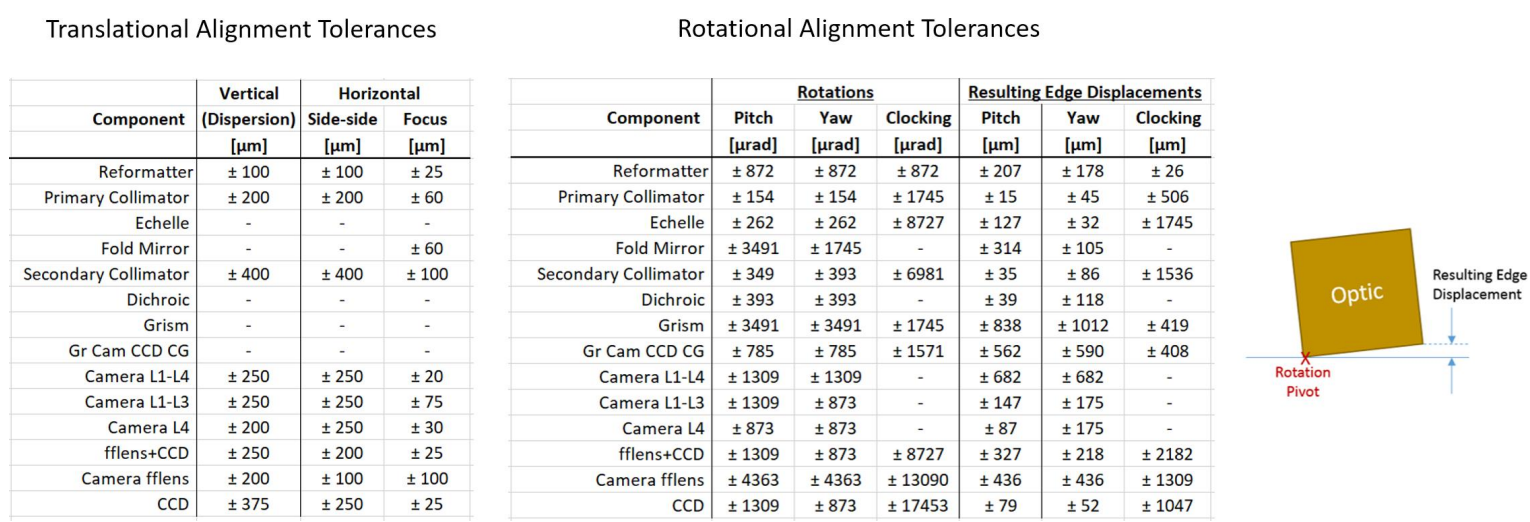

Table 1. Translational and rotational alignment tolerances.

Translational Stability Tolerances

\begin{tabular}{|c|c|c|c|}
\hline \multirow{3}{*}{ Component } & \multirow{3}{*}{$\begin{array}{c}\text { Vertical } \\
\text { (Dispersion) } \\
{[\mathrm{nm}]}\end{array}$} & \multicolumn{2}{|c|}{ Horizontal } \\
\hline & & Side-side & Focus \\
\hline & & {$[\mathrm{nm}]$} & {$[\mathrm{nm}]$} \\
\hline Reformatter & \pm 4 & \pm 100 & \pm 1000 \\
\hline Primary Collimator & \pm 2.11 & \pm 375 & \pm 2843 \\
\hline Echelle & \pm 900000 & - & - \\
\hline Fold Mirror & - & - & \pm 406.12 \\
\hline Secondary Collimator & \pm 4.32 & \pm 107.84 & \pm 840.31 \\
\hline Dichroic & - & \pm 100000 & \pm 65000 \\
\hline Grism & - & - & \pm 150000 \\
\hline Gr Cam CCD CG & \pm 3234 & \pm 70616 & \pm 100000 \\
\hline Camera L1-L4 & \pm 1.57 & \pm 35.7 & \pm 7114 \\
\hline Camera L1-L3 & \pm 2.80 & \pm 63.48 & \pm 1616 \\
\hline Camera L4 & \pm 3.58 & \pm 81.51 & \pm 1716 \\
\hline fflens $+C C D$ & \pm 1.45 & \pm 30 & \pm 1231 \\
\hline Camera fflens & \pm 58.21 & \pm 900 & \pm 2710 \\
\hline $\mathrm{CCD}$ & \pm 1.65 & \pm 15000 & \pm 900.9 \\
\hline
\end{tabular}

Rotational Stability Tolerances

\begin{tabular}{|r|cc|c|c|c|c|}
\hline & \multicolumn{3}{|c|}{ Rotations } & \multicolumn{3}{|c|}{ Resulting Edge Displacements } \\
\hline Component & Pitch & Yaw & Clocking & Pitch & Yaw & Clocking \\
\hline & {$[\mu \mathrm{rad}]$} & {$[\mu \mathrm{rad}]$} & {$[\mu \mathrm{rad}]$} & {$[\mathrm{nm}]$} & {$[\mathrm{nm}]$} & {$[\mathrm{nm}]$} \\
\hline Reformatter & \pm 6.0 & \pm 6.0 & \pm 2.5 & \pm 0.72 & \pm 0.61 & \pm 0.1 \\
\hline Primary Collimator & \pm 0.001 & \pm 0.12 & \pm 0.009 & \pm 0.07 & \pm 34 & \pm 2.5 \\
\hline Echelle & \pm 0.001 & \pm 0.21 & \pm 0.15 & \pm 0.59 & \pm 26 & \pm 29 \\
\hline Fold Mirror & \pm 0.038 & \pm 1.0 & - & \pm 3.46 & \pm 60 & - \\
\hline Secondary Collimator & \pm 0.002 & \pm 0.042 & \pm 0.032 & \pm 0.16 & \pm 9.1 & \pm 7.1 \\
\hline Dichroic & \pm 0.002 & \pm 0.042 & - & \pm 0.23 & \pm 13 & - \\
\hline Grism & \pm 0.03 & \pm 0.7 & \pm 0.007 & \pm 7.2 & \pm 189 & \pm 1.8 \\
\hline Gamer Cam CCD CG & \pm 0.004 & \pm 0.082 & \pm 0.008 & \pm 2.7 & \pm 62 & \pm 2.0 \\
\hline Camera L1-L4 $L 3$ & \pm 0.006 & \pm 0.14 & - & \pm 3.2 & \pm 73 & - \\
\hline Camera L4 & \pm 0.055 & \pm 1.1 & - & \pm 6.1 & \pm 225 & - \\
\hline fflens+CCD & \pm 0.072 & \pm 1.8 & - & \pm 7.2 & \pm 367 & - \\
\hline Camera fflens & \pm 0.376 & \pm 3.3 & \pm 0.82 & \pm 31 & \pm 816 & \pm 206 \\
\hline CCD & \pm 6.0 & \pm 29.3 & \pm 330 & \pm 38 & \pm 726 & \pm 32987 \\
\hline & & & & \pm 363 & \pm 1759 & \pm 41 \\
\hline
\end{tabular}

Table 2. Translations and rotations that independently lead to a $0.1 \mathrm{~m} / \mathrm{s}$ shift of the spectrum at the detector.

The results are shown in Table 1. These tolerance values show the primary collimator to be the most sensitive component during alignment. The secondary collimator is the second most sensitive component. The values shown for the camera internal elements will be the responsibility of the camera vendor (Winlight Systems). The values shown for the bench-mounted optics will be achieved during alignment through adjustment of the Zerodur shim stack heights (see Section 4.3 below).

\subsection{Stability Tolerances}

For the stability tolerance study, each optic was independently moved within Zemax in each of its six degrees of freedom, to determine the amount of movement required to cause a $0.1 \mathrm{~m} / \mathrm{s}$ radial velocity (RV) shift at the detector. The results are shown in Table 2. Note these are very small allowable movements. Indeed, these values drive the high mechanical stability required of KPF and all PRV spectrometers.

\section{OPTICAL BENCH MECHANICAL DESIGN}

\subsection{Overall Approach}

During an observation, the stability of an optical mount can be affected by temperature gradients within the spectrometer or the vibration environment. Mitigation of these two factors has driven the opto-mechanical design of the spectrometer (to be described within this section).

\subsection{Optical Bench}

Given the nanometer and microradian stability requirements presented in Section 3.2, expansion and contraction from temperature changes can have a significant influence on mechanical stability and therefore on the RV stability of the instrument at the sub-m/s level. Employing materials with very low coefficient of thermal expansion (CTE) values is one method of minimizing the influence of such effects. 
The KPF disk was originally purchased for the SuperNova Acceleration Probe (SNAP) project at UC Berkeley's Space Sciences Lab. Pictures of the disk are shown in Figure 3.
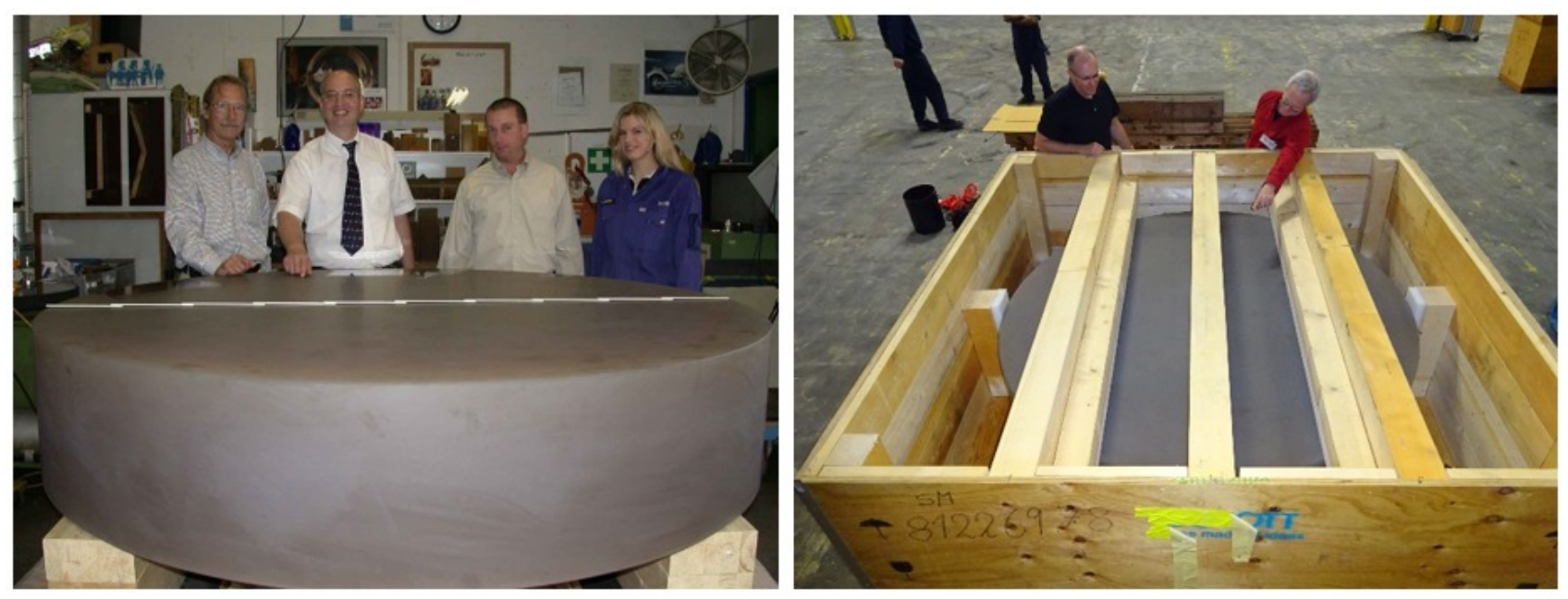

Figure 3. Left: the KPF disk at Schott in Germany. Right: The KPF disk in its shipping crate, during a visit by the KPF team.

A test report prepared by Schott on the SNAP blank indicates that the measured CTE of the KPF disk is smaller than $0.0 \pm 0.005 \times 10^{-6} \mathrm{~K}^{-1}$. Table 3 puts this number in perspective, in that the KPF disk has a lower CTE than the lowest-expansion class of non-custom Zerodur available (Class 0 EXTREME).

\begin{tabular}{ll}
\hline \hline \multicolumn{1}{c}{ CTE Grade } & \multicolumn{1}{c}{$\mathrm{CTE}\left(0^{\circ} \mathrm{C}\right.$ to $\left.50^{\circ} \mathrm{C}\right)$} \\
\hline Expansion Class 2 & $0.0 \pm 0.1 \times 10^{-6} \mathrm{~K}^{-1}$ \\
Expansion Class 1 & $0.0 \pm 0.05 \times 10^{-6} \mathrm{~K}^{-1}$ \\
Expansion Class 0 & $0.0 \pm 0.02 \times 10^{-6} \mathrm{~K}^{-1}$ \\
Expansion Class 0 SPECIAL & $0.0 \pm 0.01 \times 10^{-6} \mathrm{~K}^{-1}$ \\
Expansion Class 0 EXTREME & $0.0 \pm 0.007 \times 10^{-6} \mathrm{~K}^{-1}$ \\
KPF Disk & $0.0 \pm 0.005 \times 10^{-6} \mathrm{~K}^{-1}$ \\
Expansion TAILORED & Optimized for application \\
\hline
\end{tabular}

Table 3. Zerodur CTE grades available at $\mathrm{Schott}^{3}$. To determine the CTE, the length of the sample was measured at two temperatures $\left(0^{\circ} \mathrm{C}\right.$ and $\left.50^{\circ} \mathrm{C}\right)$.

A list of materials typically used for optical benches is given in Table 4. This table shows that for a given temperature change, our Zerodur bench will expand or contract many orders of magnitude less than benches constructed of other materials.

\subsubsection{Bench Vibration Considerations}

Vibration requirements The vibration requirements for KPF are divided into three performance categories (as shown in Table 5): Operational, Non-Operational, and Survival.

Operational Vibration Isolation of the Bench The optical bench will be supported by five Minus-K CM-1 vibration isolators, as shown in Figure 4. The transmissibility function for the CM-1 and SM-1 isolators is shown below in the left panel of Figure 5. There are no transmissibility numbers provided by the manufacturer above $100 \mathrm{~Hz}$. Above $100 \mathrm{~Hz}$ we are currently simply using a flat line at the last known transmissibility value. While this is an underestimation at some frequencies, there is little known input content in the requirements or our 


\begin{tabular}{ccc}
\hline \hline Material & $\begin{array}{c}\mathrm{CTE} \\
{\left[10^{-6} \mathrm{~K}^{-1}\right]}\end{array}$ & $\begin{array}{c}\text { Relative to } \\
\text { KPF Disk }\end{array}$ \\
\hline Zerodur (KPF disk) & $<0.005$ & $1 \mathrm{x}$ \\
Invar 36 & 1.0 & $200 \mathrm{x}$ \\
Stainless 416 & 8.5 & $1700 \mathrm{x}$ \\
Stainless 304 & 14.7 & $2940 \mathrm{x}$ \\
Aluminum 6061 & 23.6 & $4720 \mathrm{X}$ \\
\hline
\end{tabular}

Table 4. CTE values for materials typically employed as optical benches. Zerodur CTE value from Schott measurement of the KPF disk; other CTE values from Paquin (1997). ${ }^{4}$

\begin{tabular}{|c|c|c|c|c|c|}
\hline \multicolumn{6}{|c|}{ KPF Seismic Performance Requirement Categories } \\
\hline \multirow{2}{*}{$\begin{array}{l}\text { Performance } \\
\text { Category }\end{array}$} & \multirow{2}{*}{$\begin{array}{c}\text { Seismic Requirement } \\
\text { Source }\end{array}$} & \multirow[b]{2}{*}{ Location } & \multicolumn{2}{|c|}{ Peak Accelerations (g) } & \multirow{2}{*}{ Performance Requirement } \\
\hline & & & $\begin{array}{l}\text { Before } \\
\text { Isolators }\end{array}$ & After Isolators & \\
\hline Operational & $\begin{array}{c}\text { KPF In Situ } \\
\text { Measurements }\end{array}$ & Basement & 0.01 (grms & $0.001\left(\mathrm{~g}_{\mathrm{rms}}\right)$ & $\begin{array}{c}\text { No Impact to Science } \\
\text { Gathering }\end{array}$ \\
\hline Non-Operational & $\begin{array}{c}200 \text { Year Seismic, URS } \\
\text { TMT Study, Modified for } \\
\text { Keck Site }\end{array}$ & Basement & 0.6 & 0.6 & $\begin{array}{c}\text { Science Gathering Interupted } \\
\text { During Event and Resumes } \\
\text { After Event with No Action } \\
\text { Needed }\end{array}$ \\
\hline Survival & $\begin{array}{c}500 \text { Year Seismic, URS } \\
\text { TMT Study, Modified for } \\
\text { Keck Site }\end{array}$ & Basement & 0.92 & 0.92 & $\begin{array}{l}\text { No Catastrophic Failure or } \\
\text { Risk to Personel, May } \\
\text { Require Repair }\end{array}$ \\
\hline
\end{tabular}

Table 5. KPF vibration requirement categories
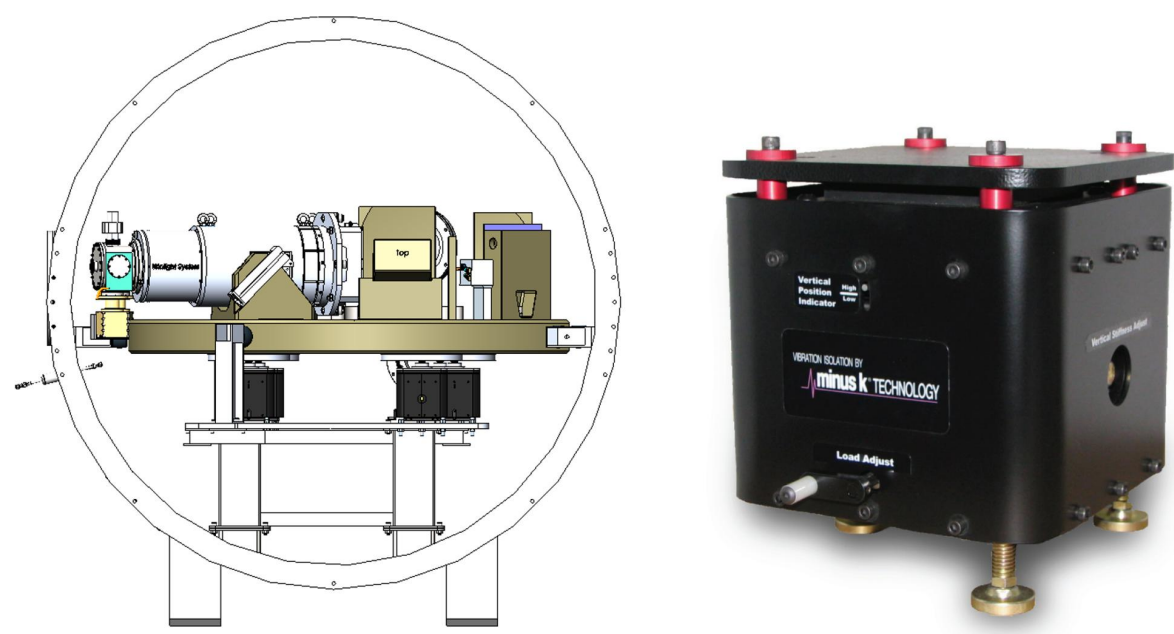

Figure 4. Left: Optical bench mounted in chamber with vibration isolators. Right: Minus K CM-1 vibration isolator 

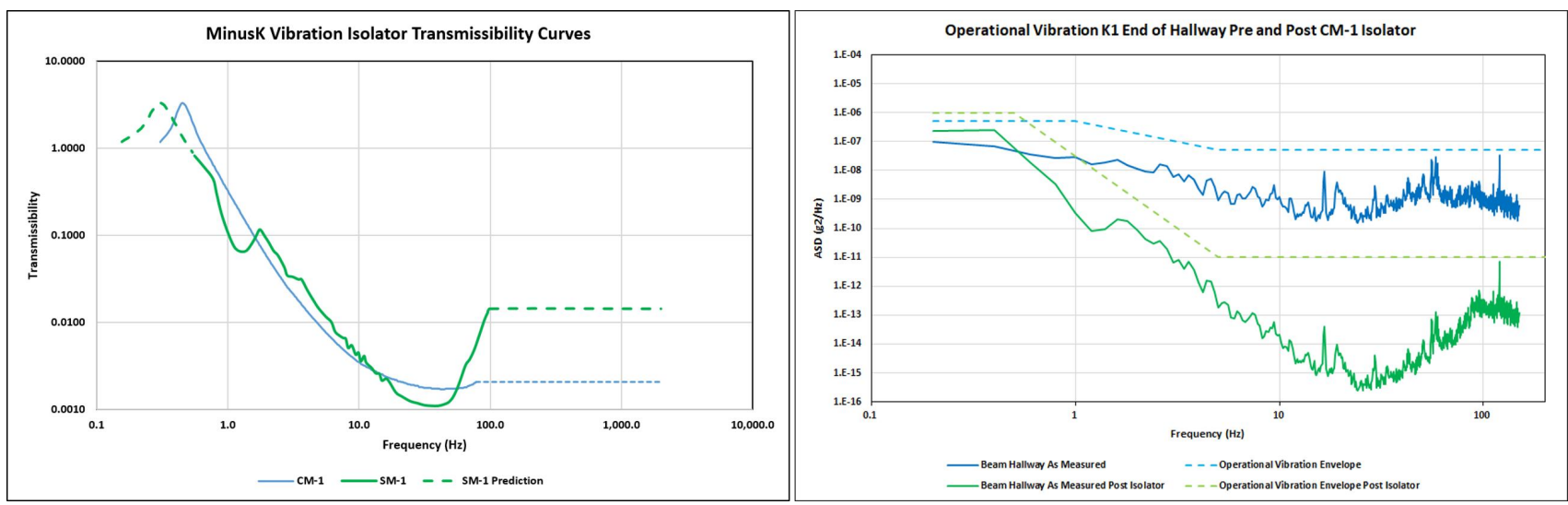

Figure 5. Vibration isolators transmissibility and operational vibration environment at the K1 end of the hallway

measurements above $100 \mathrm{~Hz}$. We apply the transmissibility curve that is a composite of the solid and dashed green lines to the requirements for elements that are mounted to this isolation system.

In the operational performance category, the KPF instrument must operate with no impact to science gathering. The requirements are based on in-situ vibration measurements made at the spectrometer installation location at the end of the basement hallway. Figure 5 shows the peak acceleration spectral density (ASD) measured in the hallway and the corresponding post CM-1 isolator ASD. The pre- and post-isolator operational envelope shown represents the requirement levied on the instrument. The max design acceleration for pre-isolator operational envelope is $0.007 \mathrm{~g}_{\mathrm{RMS}}$ and for the post-isolator envelope is $0.001 \mathrm{~g}_{\mathrm{RMS}}$.

Non-Operational and Survival Vibration Bench Constraints The non-operational and survival vibration requirements were provided by the W.M. Keck Observatory and derived from the URS TMT study, ${ }^{5}$ modified for the Keck site-specific soil conditions. Unlike the operational requirements, these inputs are not filtered through the instrument isolators for the bench and any components mounted on the bench. This is because the isolators can not accommodate the deflections, Figure 6, seen under earthquake loads. They will bottom out and pass full accelerations into the spectrometer. The non-operational requirement is based on a probabilistic seismic hazard analysis with an average 200-year return period. The survival requirement is based on an average 500-year return period. Horizontal and vertical inputs were supplied, but we are only using the horizontal values, which are greater than the vertical values and therefore conservative. These inputs and their post isolator values are shown in Figure 6 below. The corresponding peak accelerations are shown in Table 5. To accommodate these survival accelerations the bench is constrained by seven elastomeric profile dampers shown in Figure 7. These dampers are mounted with clearance to the bench. Under operational accelerations they do not touch the bench and therefore do not short circuit the vibration isolators.

\subsubsection{Zerodur Disk Modifications}

The KPF disk is currently a cylinder with a diameter of $1997.8 \mathrm{~mm}$ and a thickness of $400.6 \mathrm{~mm}$. The mass of the disk is $3177 \mathrm{~kg}(7004 \mathrm{lbs})$. Given our access restrictions to the basement, as well as the difficulties of moving the large mass of the complete disk, we will modify the disk shape, as shown in Figure 8.

We first slice a D-shaped piece off of this full sized disk to use as substrate material for some of the optics. The D-cut block of glass is further sliced into pieces to create the blanks for the echelle base, the secondary collimator, the reformatter base, and the intermediate fold mirror.

The remaining disk is sliced into thirds. The top and bottom slices become the spectrometer bench and a blank for another bench as a backup. The middle slice is used to extract the blank for the primary collimator and serve as a backup source for other optics if required, see Figure 8.

Slicing the disk into thirds reduces the bench mass significantly and the D-cut reduces the bench dimension, allowing it to more easily fit through the WMKO access hatches and doors. Using the D-shaped offcut for the 


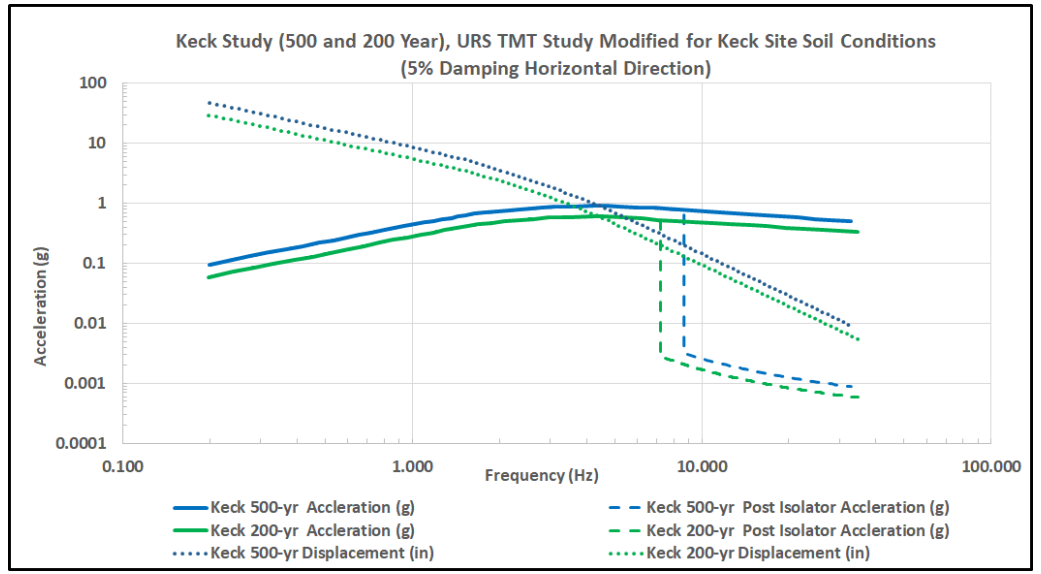

Figure 6. Non-operational and survival vibration environment for Keck basement

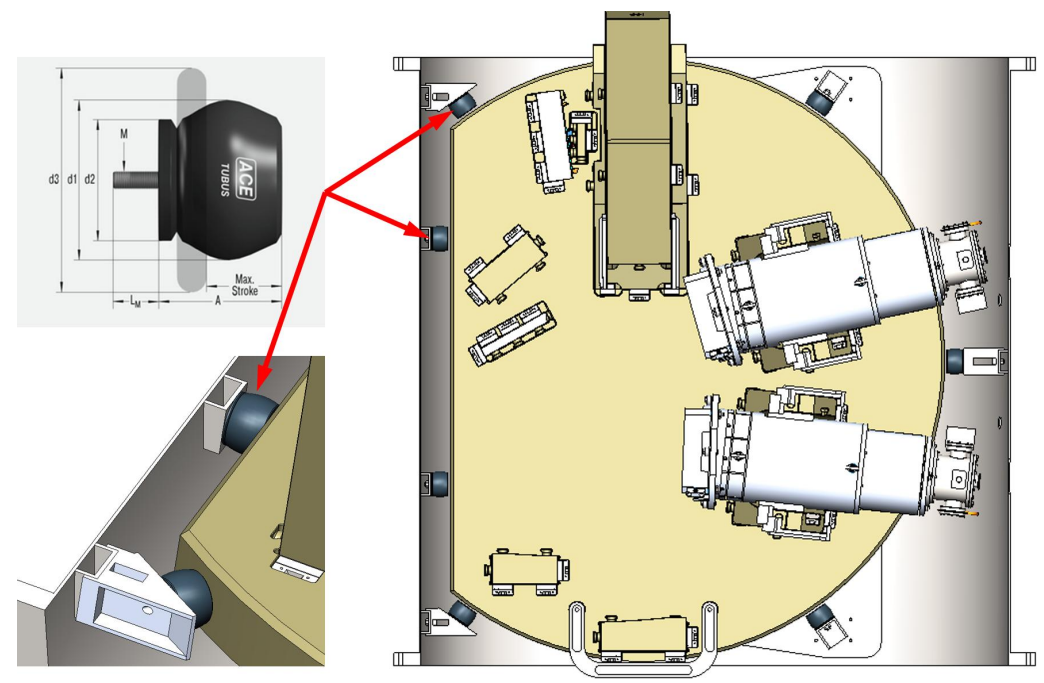

Figure 7. KPF optical bench earthquake restraints 
mirror substrates has two advantages: material cost savings and stability (through utilizing the extremely low CTE Zerodur).
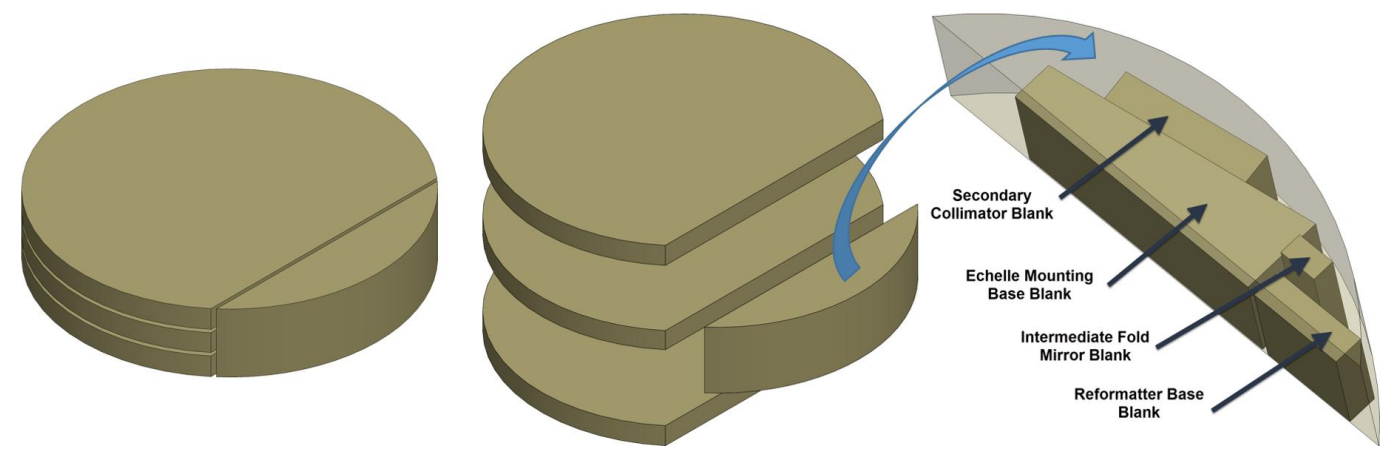

Figure 8. Zerodur disk cut plan

\subsection{Optical Mounts}

This section will describe the designs of the various optical mounts. For reference, an overview of the KPF spectrometer is shown in Figure 2.

\subsubsection{General Mounting Approach}

The optical component mounting design takes advantage of the low CTE of Zerodur by having only Zerodur elements control the position of the optics. Zerodur optics are mounted in a Zerodur bench with Zerodur shims between them (with springs providing the retention force). The bench has pockets milled into it (as shown in the left of Figure 9) for mounting each optical component. As shown in the right side of that figure, there are six pairs of shims used to position an optic (or mount) within each pocket. Each component has horizontal spring units to hold it in place against the horizontal shim stacks under the design loads. Some, but not all, of the components have vertical spring clamps as well (if the design loads require them).
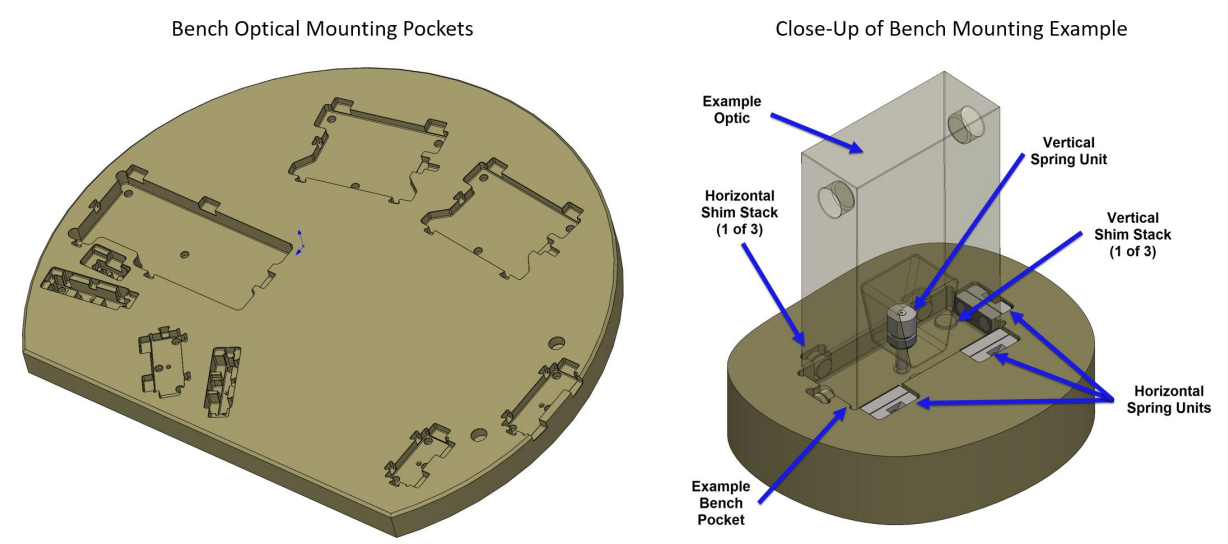

Figure 9. Optical mounting pockets in spectrometer optical bench (left), Example mount (right)

The springs for each optical component are set to different values demanded by the mounting configuration and mass of each individual optic and what is required by the design loads. Some optics have center of mass heights that are higher relative to the counter-moment footprint of the optic. The primary collimator, for example, is a relatively tall and large optic with a narrow footprint in the direction of its optical axis. This requires a higher vertical spring force to counteract horizontal accelerations during an earthquake. The echelle mount has a footprint that is wide compared to the height of its center of mass and does not require a vertical hold down spring. Its own weight is sufficient. Table 6 below shows the result of these calculations for the primary collimator. As can be seen, the weight of the primary collimator at $300 \mathrm{~N}$ is not sufficient to prevent 
the optic from tipping in the clocking direction $(511 \mathrm{~N})$ or in the pitch direction $(2162 \mathrm{~N})$. Therefore a vertical spring of at least $1862 \mathrm{~N}$ is required. This is the max spring load required in any direction for all of the optics and therefore defines one of the limiting cases.

\begin{tabular}{|c|c|c|c|c|c|c|}
\hline \multicolumn{7}{|c|}{ Primary Collimator } \\
\hline Dimension & $\begin{array}{c}\text { Distance } \\
\text { (mm) }\end{array}$ & $\begin{array}{l}\text { CG Height } \\
(\mathrm{mm})\end{array}$ & $\begin{array}{c}\text { Unreleived } \\
\text { Mass } \\
\text { (kg) }\end{array}$ & $\begin{array}{c}\text { Mass } \\
(\mathrm{kg})\end{array}$ & $\begin{array}{l}\text { Normal } \\
\text { Force, } \\
\text { Weight } \\
\text { (N) }\end{array}$ & $\begin{array}{l}\text { Required } \\
\text { Spring } \\
\text { Force per G } \\
\text { Load Axis } \\
\text { (N) }\end{array}$ \\
\hline Base Pad Depth, Z (Pitch Rotation about X): & 59.400 & 232.7 & 30.58 & 30.58 & 300 & 2162 \\
\hline Base Pad Width, X (Clock Rotation about Z): & 251.400 & 232.7 & 30.58 & 30.58 & 300 & 511 \\
\hline Horizontal Translation $\mathrm{X}$ and $\mathrm{Z}$ : & & & 30.58 & 30.58 & 300 & 276 \\
\hline
\end{tabular}

Table 6. Required mounting forces for the primary collimator

\subsubsection{Mounting Shims}

The mounting interface for each optic is controlled by six sets of Zerodur shims. One of these shims has a two-meter diameter spherical cap on one end, Figure 10. This spherical face contacts the flat face of the other shim. The spherical interface allows small misalignments in planarity between the bench and the optic of $+/-0.5$ degrees to exist without forming an uncontrolled line or point contact in the interface. The other two interfaces of shim-to-bench and shim-to-optic are flat on flat. In addition to accounting for small misalignments, the sphereon-flat Hertzian contact between the shims is the highest stress in the system. This makes a failure more likely to occur in the shims than in the much more expensive bench or optics. During the initial alignment and integration of the spectrometer, shims will be chosen from a variety of available sizes and if necessary, individually ground to the thickness required for alignment.

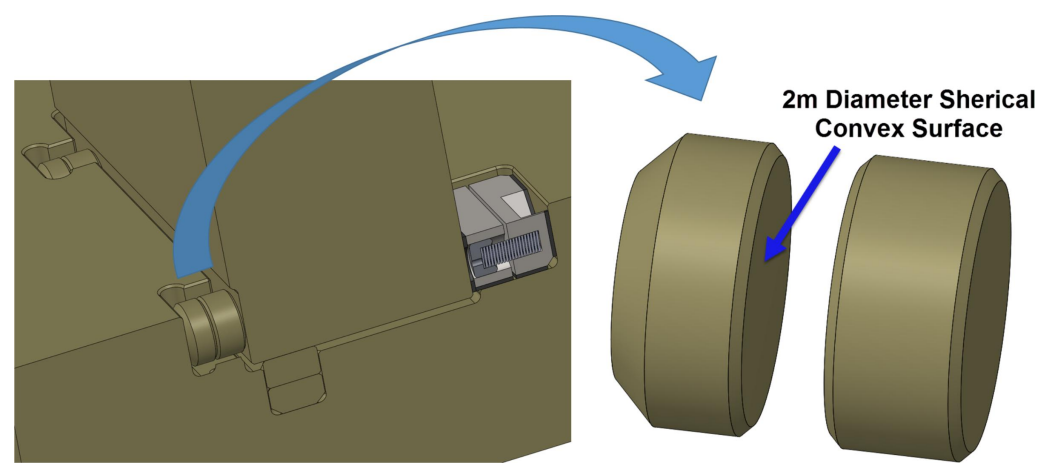

Figure 10. Mounting shim stack

\subsubsection{Mounting Springs}

All of the optics and optic mounts are held against the locating shims with spring assemblies. There are two different types of horizontal spring assemblies and two different types of vertical spring assemblies. All of these springs are adjustable and can be set to deliver exactly the force required per direction and per optic. To aid integration of the mount assemblies, each spring has a lockout screw or cam that activates and deactivates the spring assembly.

Type I Horizontal Spring The Type I horizontal spring assemblies constrain all of the optics and optic mounts that interface directly to the bench in the horizontal plane. Each assembly has two springs in it. These springs are tuned to the total load required and balanced with each other in a spring tuning assembly that utilizes two force transducers. Viton pads protect the interface at the optic and bench. See Figure 11. 


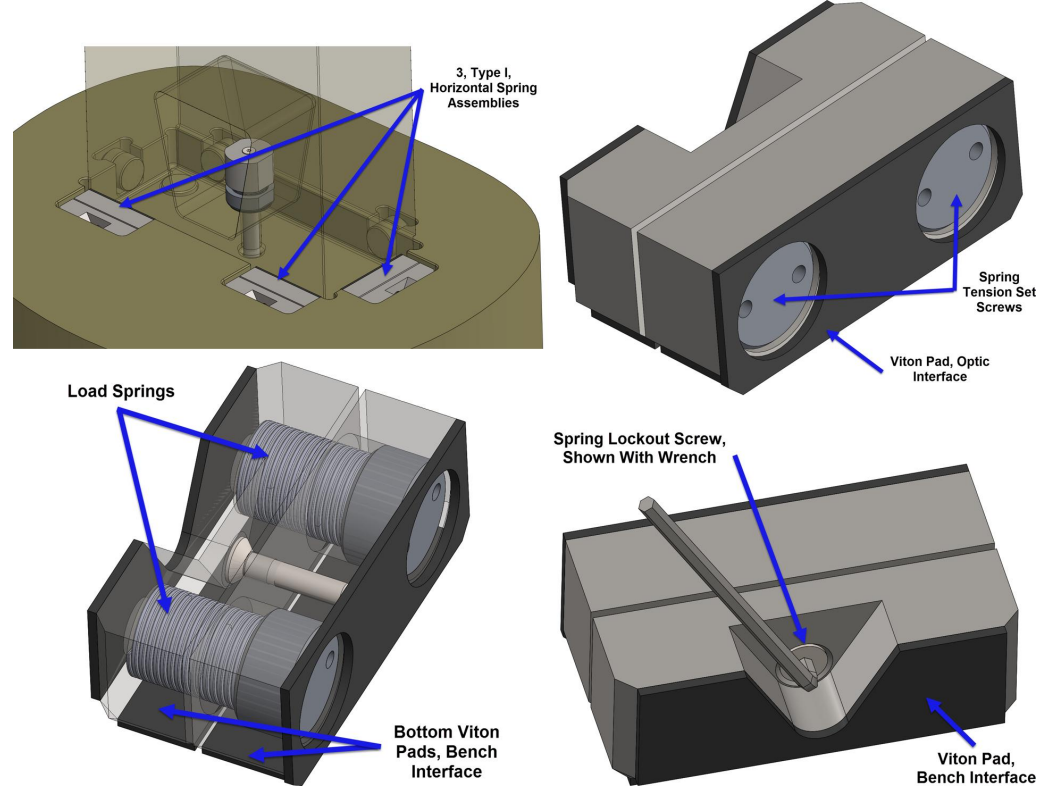

Figure 11. Type I horizontal spring assembly

Type II Horizontal Spring Type II horizontal spring assemblies use the same spring block as Type I horizontal springs, but they have an arm that allows them to function as a C-Clamp. These springs shown in Figure 12 are used to hold the echelle to its mounting base and the camera to its mounting base. The clamp arm is slightly modified between the camera and echelle mount to fit those individual assemblies. Lockout and spring adjustment is identical to the Type I horizontal spring assembly.

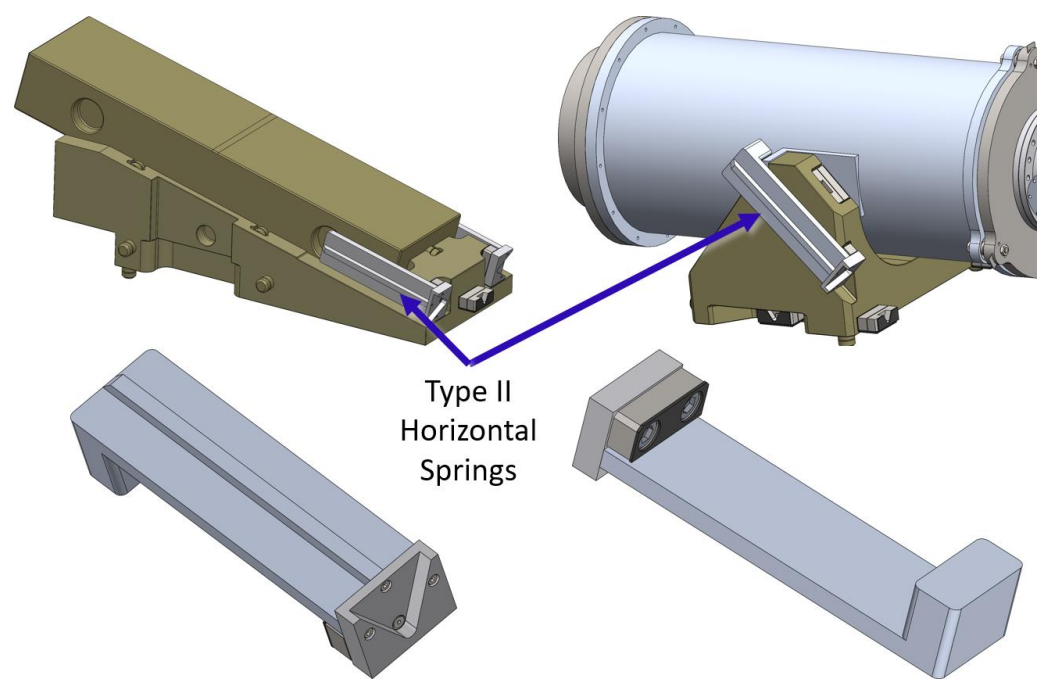

Figure 12. Type II horizontal spring assembly

Type I Vertical Spring The Type I vertical spring assemblies pull the large mirrors (primary collimator, secondary collimator, and red fold mirror) downwards against the vertical shim stacks, and prevent these optics from tipping over under earthquake loads. They feature a single spring that is adjusted to the load required using a tuning assembly before mounting. This spring has a screw to engage and release the spring that is accessible from the top of the bench. There is a threaded rod that passes through the bench with ample clearance and a nut on the other side used to adjust the spring force. The threaded rod and bottom nut must be in place before 
the optic is lowered onto the bench so there is a PEEK keeper that slides into the bench pocket on the bottom. This keeper has an O-ring that interfaces with the wall of the pocket to hold the keeper in place. The keeper and the O-ring have been sized to account for the differential thermal expansion. The assembly does not require access to this nut under the bench when tightening the upper retention assembly. See Figure 13.
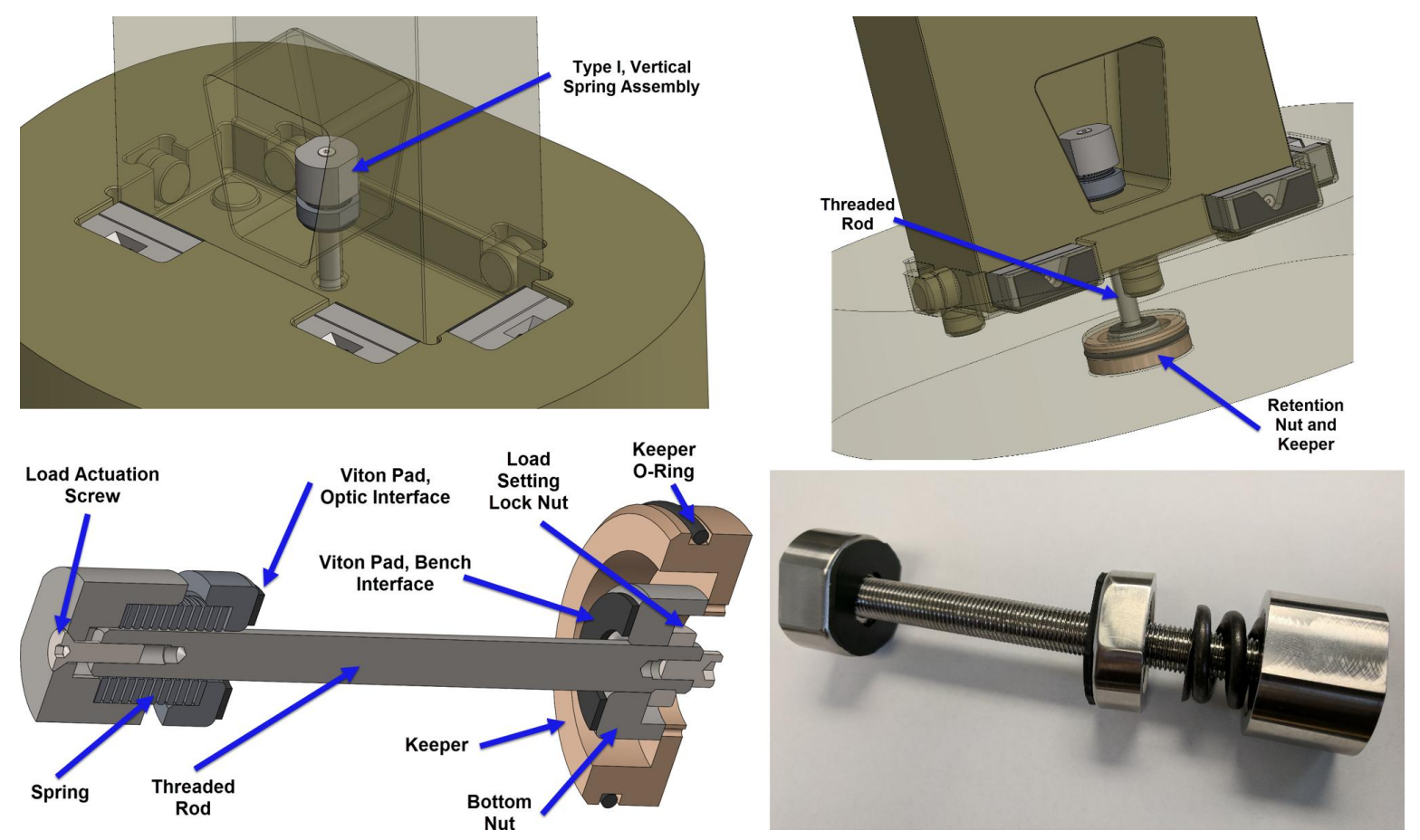

Figure 13. Type I vertical spring assembly and engineering test unit (ETU)

Type II Vertical Spring The Type II vertical spring is used in the remaining smaller optics. These have a different constraint system in the pockets so do not require as large a vertical spring to keep them from tipping over. These provide relatively small vertical loads from 8 to $25 \mathrm{lbs}$. Due to the smaller size of these optics the spring is moved to the bottom of the bench and load is activated by a cam cylinder inside a hole in the optic. The cam rides inside two Vespel SP3 sleeves which apply the force to the optic. SP3 is a low friction version of Vespel. The vertical rod is a loose fit to the hole in the optic but as added protection a Viton sleeve wraps around the rod where it passes through the glass. Like the Type I, these have a keeper to prevent the assembly from dropping out of the bottom of the bench when the optics are mounted and dismounted from the bench. See Figure 14.

\subsubsection{Large Mirror Mounting}

The primary collimator, secondary collimator, and red fold mirror all share the same mounting method. They all use Type I horizontal and vertical spring assemblies and share a three point shim constraint on the bottom, a double shim constraint at the front, and a single shim constraint on the side. The primary collimator is unique among these three optics as it is mounted at the outer edge of the bench and uses an outrigger to contain the springs. The primary collimator is also the heaviest and tallest optic with a relatively small footprint and therefore has the highest shim loading under earthquake loads. The spring retention outrigger fits into two additional holes in the bench. This interface is protected by a Viton pad. See Figure 15 and Figure 16.

\subsubsection{Small Optic Mounting}

The dichroic, intermediate fold, and reformatter are all very narrow optics that are less massive than the large mirrors referenced above. All of these optics have an insufficient width at their base to be constrained from 


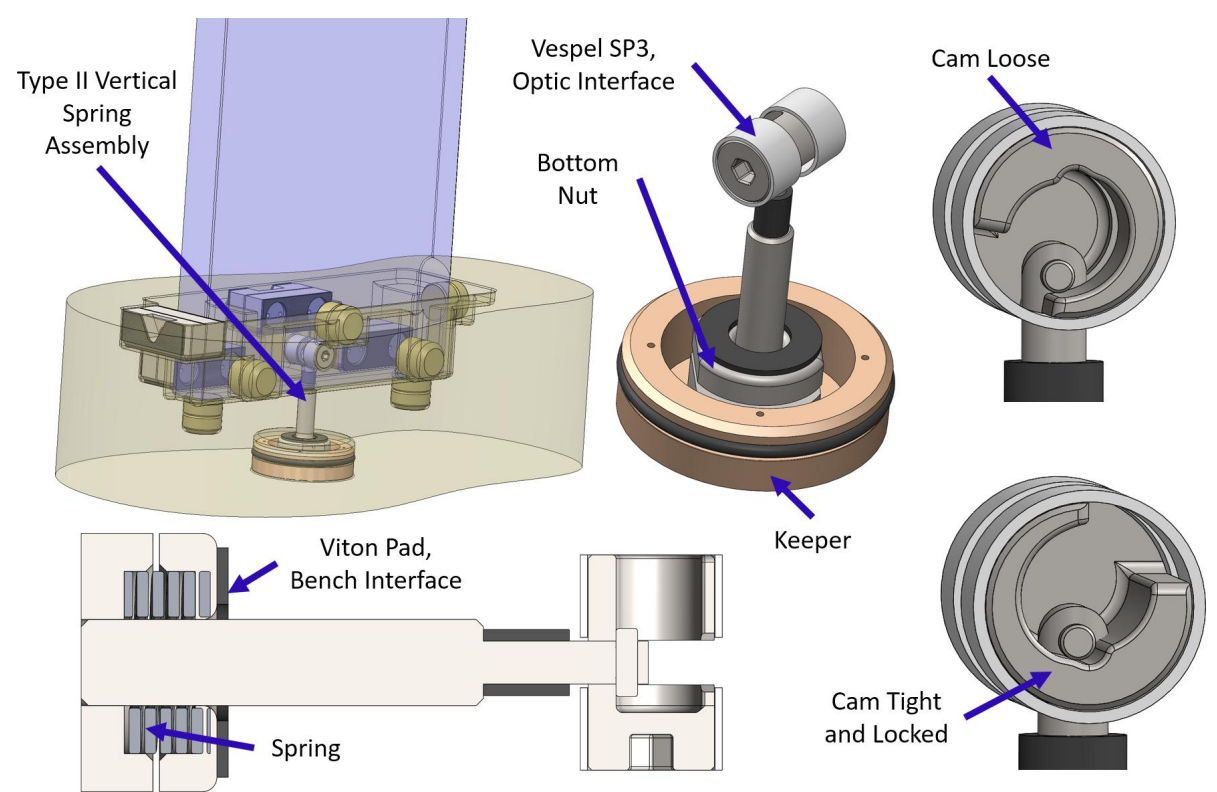

Figure 14. Type II vertical spring assembly and ETU

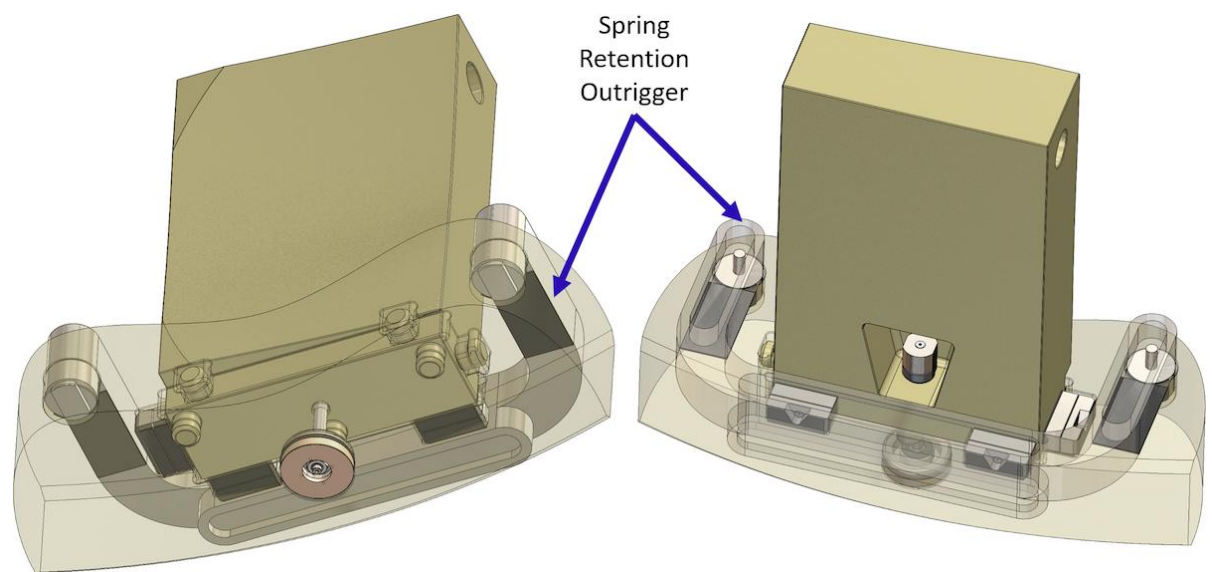

Figure 15. Primary collimator mounting
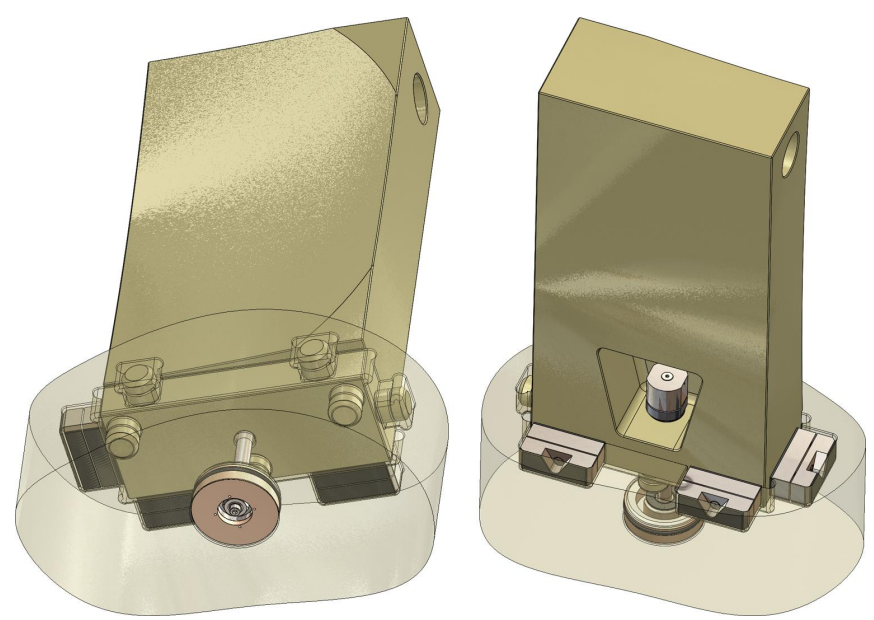

Figure 16. Secondary collimator mounting 
tipping by three shims and a vertical pull down spring in the same way the larger optics are. Instead, these three optics use three shims mounted in a triangle pattern on their front side to resist tipping forces. This requires a deeper pocket that needs to contain one or three Type I horizontal springs, as evident in the dichroic mount (Figure 17). These optics do require a vertical spring force to prevent either clocking in the dichroic (13 lbs) or pitch rotation in the intermediate fold $(23 \mathrm{lbs})$ and the reformatter $(8 \mathrm{lbs})$ under earthquake loads.

To reduce bending, the horizontal springs are placed directly opposite the horizontal shims for the dichroic and the reformatter. However, there is insufficient room to do the same for the intermediate fold mirror, and it has one spring located in the center of the shim retention triangle. Fortunately, the intermediate fold mirror is the lightest optic on the bench and requires very low loads to retain it, reducing the bending to acceptable values, see Figure 18.

The reformatter base is L-shaped to account for lack of mounting real estate on the bench in this crowded area, but it uses the same mounting method as the dichroic. Retention forces are relatively low despite its oddly located center of mass, see Figure 19.
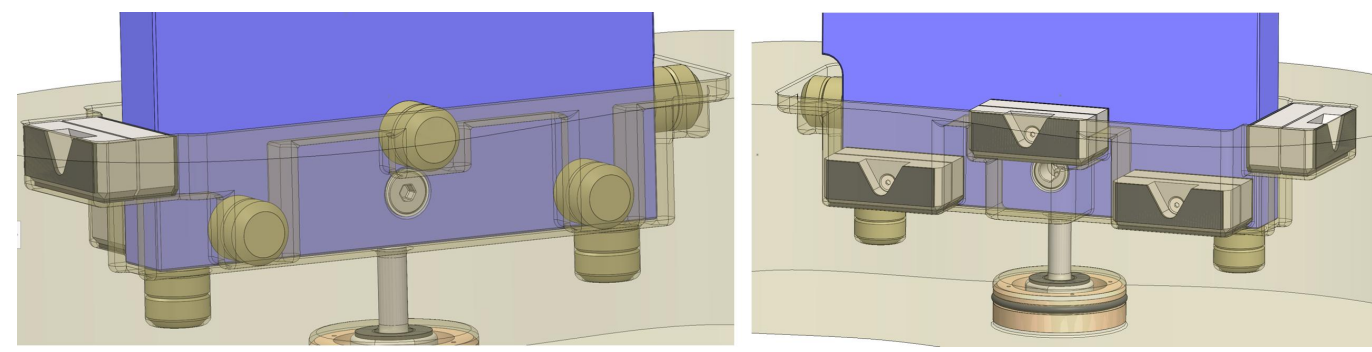

Figure 17. Dichroic mounting
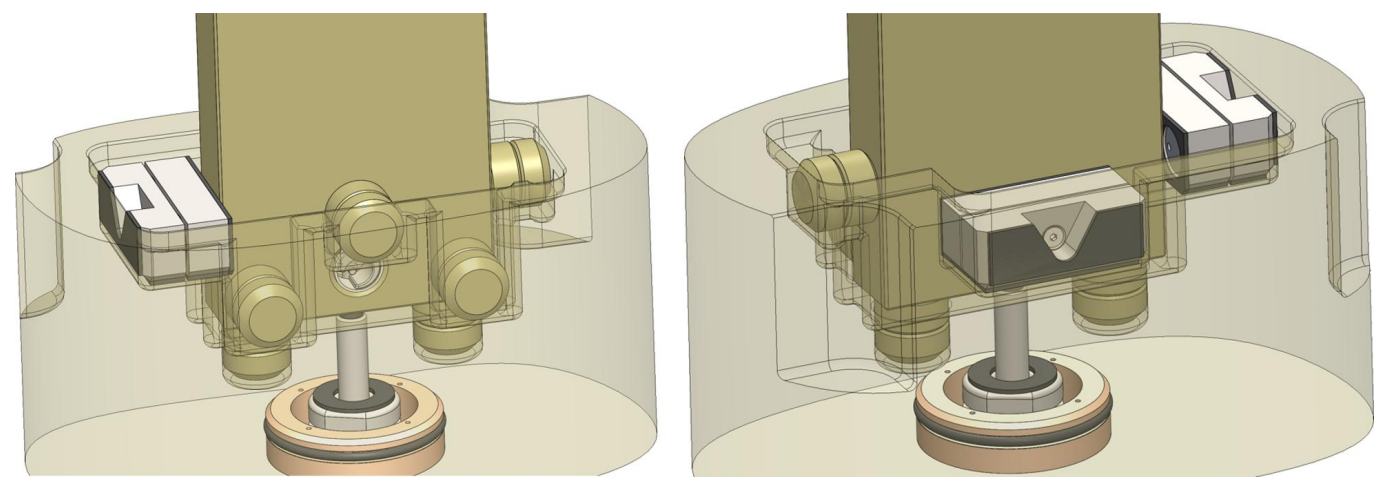

Figure 18. Intermediate fold mirror mounting

\subsubsection{Echelle Mounting}

There are two mounting interfaces for the echelle. First the echelle mounts to its base and then the base mounts to the bench. Both the echelle mount and the echelle base mount are simplified by the fact that they do not need a vertical retention spring (owing to their base shims being sufficiently far apart given their center of mass height).

The echelle is mounted to its Zerodur base by two Type I horizontal springs and two Type II horizontal springs, see Figure 20. The bottom shim points are chosen to minimize surface deflection. Depending on schedule, there may be an opportunity to tune these support locations to partially neutralize surface figure error in the manufactured echelle. In the current location, max surface height difference when mounted is $243 \mathrm{~nm}$. The lower horizontal restraint shim and the Type II spring force are purposely misaligned to make sure they do not provide any uplift force to the echelle due to spring inconsistency. This misalignment produces a small moment forcing the echelle into its base. 


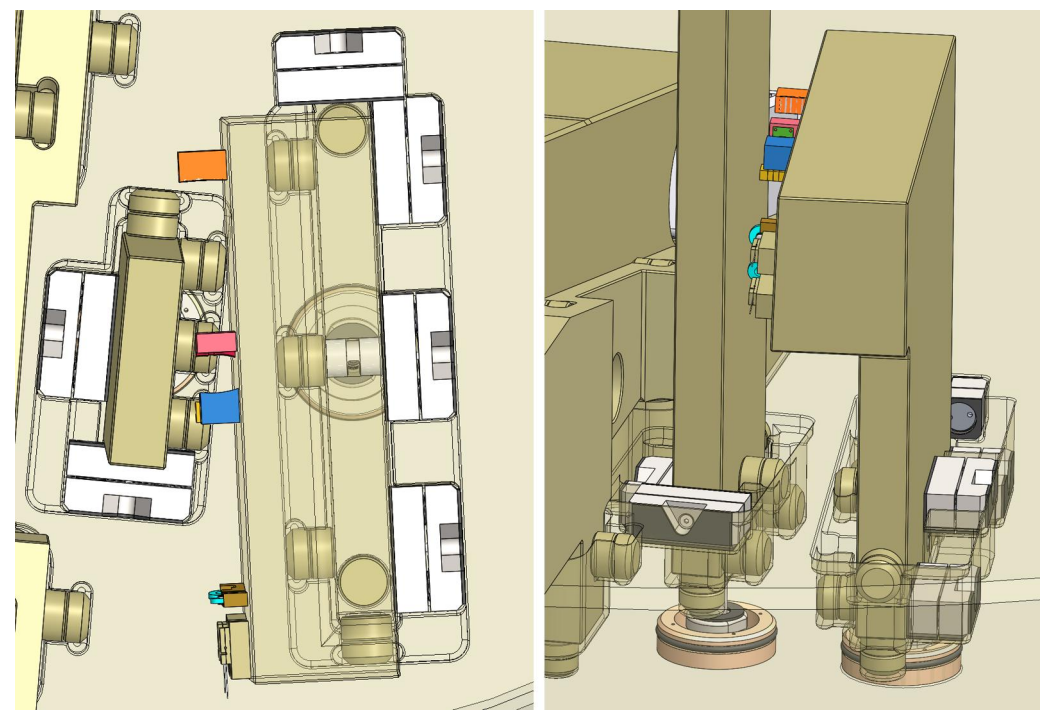

Figure 19. Reformatter mounting area congestion on the bench
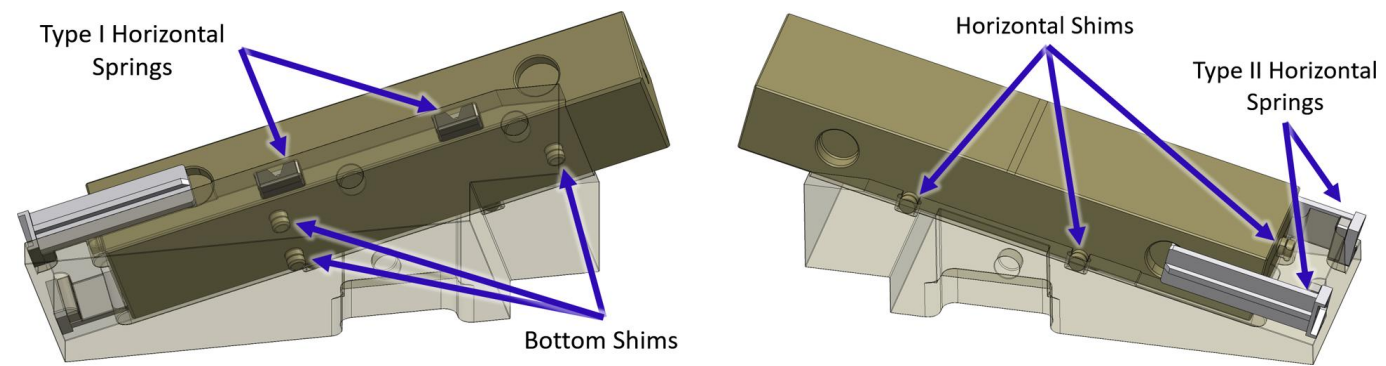

Figure 20. Echelle mounting

The echelle base is held within its bench pocket by three Type I springs (Figure 21). There is no vertical spring as weight is sufficient to resist tipping moments. Bottom shims and side shims are symmetric about the completed assembly's center of mass.
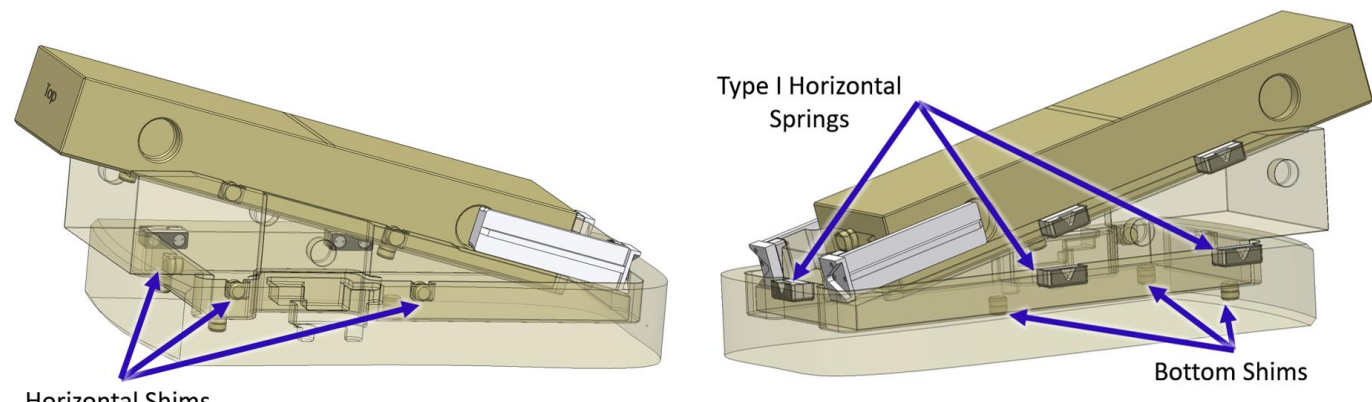

Figure 21. Echelle base mounting

\subsubsection{Camera Bench Mounting}

Like the echelle, there are two mounting interfaces for the camera. The camera mounts to the camera base and the camera base mounts to the bench. Neither of these interfaces require dedicated vertical spring force to reduce tipping moments, though the camera mount does employ some vertical hold down force.

The camera mount base is made of one large machined piece of Zerodur glass. The camera barrel (a passivelyathermal assembly designed by Winlight Systems) is mounted to this base with one Type I and two Type II 
horizontal springs. Four shims contain each end of the camera "axle" in the horizontal and vertical direction. A single shim on the side of the camera barrel constrains it in the horizontal direction and a single shim in the base constrains a tab extending down from the camera barrel to prevent camera pitch angle changes, see Figure 22 .

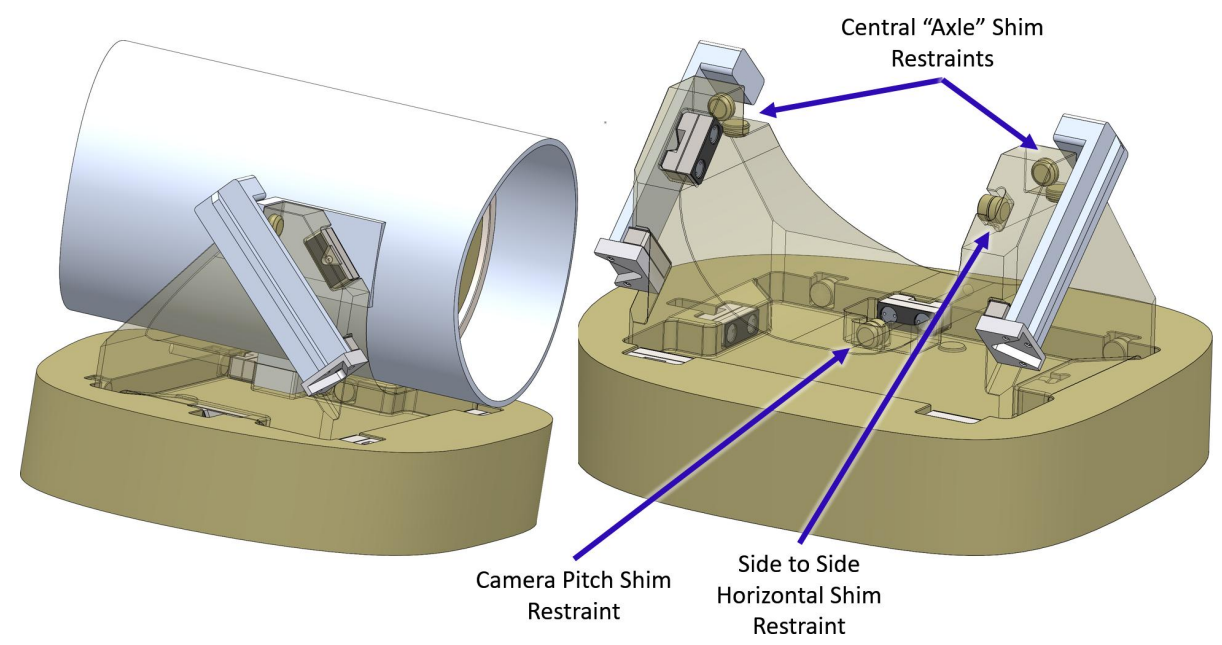

Figure 22. Camera mounting

The camera base is mounted to the bench rather simply by three Type 1 horizontal springs. Three shim stacks restrain the base vertically and three shim stacks constrain the base horizontally, see Figure 22. Shim adjustment for the camera can be done at any of the interfaces if needed. The current integration plan is to mount the base in the bench at the expected camera position and then adjust the camera interface shims as needed.

\section{ANALYSIS AND TESTING}

\subsection{Zerodur Material Properties}

A brittle material's strength depends on the number and size of flaws at the completion of manufacture. Dimensionally-small flaws produce lower stress concentrations and therefore grow more slowly under stress than do larger flaws. A flaw will grow more quickly under higher stress, but it will still grow under lower stress, just at a lower rate. Since all materials have flaws, failure prediction is based on statistical analysis of failures at given loads. Weibull two-parameter or three-parameter probability distributions are commonly used. However, Schott testing has shown a better prediction using three parameter Weibull distributions, and that approach is adopted here (Schott TIE-33 ${ }^{6}$ and Figure 23). Manufacturing practice concentrates on reducing the maximum size of flaws by grinding glass in steps from the largest grain size to the smallest grain size. After the final shape has been achieved through grinding, further reduction in flaw size can be achieved by polishing or acid etching the remaining surfaces.

Since flaws, regardless of their size, grow under stress, every piece of brittle material has a lifetime limit based on: the size of the flaws at the start of its life; the constant stress it is under throughout that life; and its total lifetime. To account for this, KPF uses two sets of design stresses. One is for short duration loads and one is for long duration loads using a 30 year life span based on data in Schott TIE-33. ${ }^{6}$ The lifetime data for etched D64 is shown in Figure 24.

For the KPF design we currently call out three separate manufacturing processes depending on the strength required. Grinding is specified based on DIN 848 diamond tool grain size. The main bench surfaces are ground to D151, as they see the lowest stress. All of the bench pockets, optics and optic mounts are ground to D64, as this is where the distributed mounting loads are seen. The shims see the highest stresses and are ground to D64 and then acid etched to remove at least 70 micrometers of material to remove the D64 tool marks. The values KPF has adopted for allowable stresses are shown in Table 7. It should be noted that limits on compressive stress are not known but assumed here to be at least 10 times the tensile stress limit for completeness. 


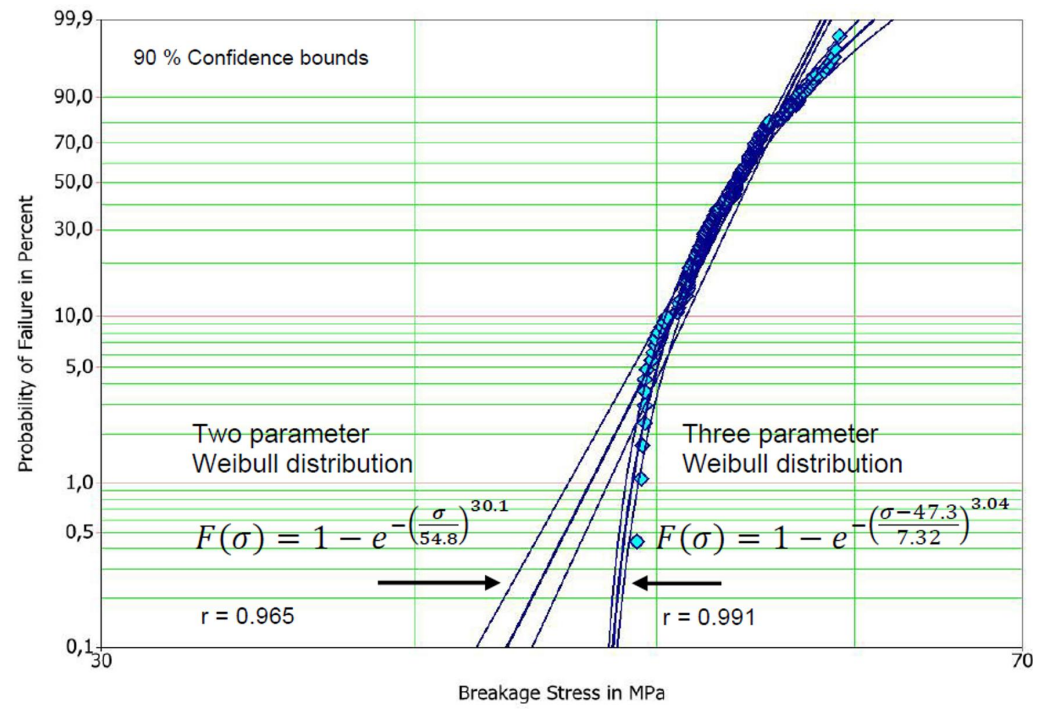

Figure 23. Zerodur ground with D151 diamond grains data set with 157 specimens 2P and 3P Weibull distribution fitted (from Schott TIE- $33^{6}$ ).

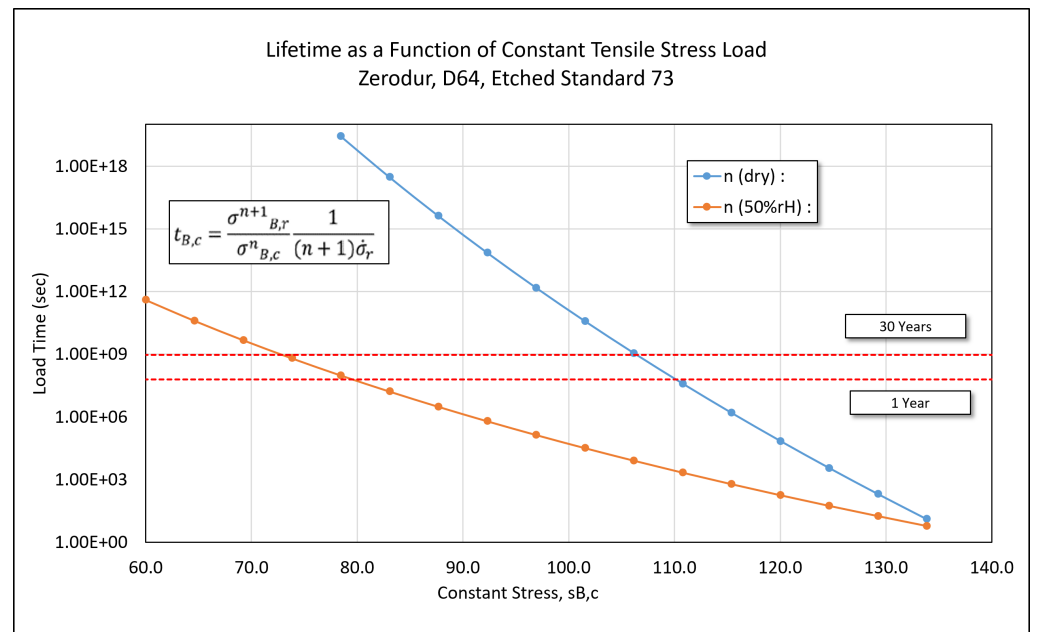

Figure 24. Lifetime as a function of constant tensile stress load, Zerodur, D64, etched standard 73.

\begin{tabular}{|c|c|c|c|c|c|c|}
\hline \multirow{2}{*}{ Preparation } & \multicolumn{2}{|c|}{$\begin{array}{c}\text { Long Duration Loads } \\
\text { (3 yrs 50\% rH) }\end{array}$} & \multicolumn{2}{c|}{$\begin{array}{c}\text { Long Duration Loads } \\
\text { (30 yrs Dry/Vacuum) }\end{array}$} & \multicolumn{2}{|c|}{ Short Duration Loads } \\
\cline { 2 - 7 } & $\begin{array}{c}\text { Allowable } \\
\text { Tensile } \\
\text { Stress }\end{array}$ & $\begin{array}{c}\text { Allowable } \\
\text { Compressive } \\
\text { Stress }\end{array}$ & $\begin{array}{c}\text { Allowable } \\
\text { Tensile } \\
\text { Stress }\end{array}$ & $\begin{array}{c}\text { Allowable } \\
\text { Compressive } \\
\text { Stress }\end{array}$ & $\begin{array}{c}\text { Allowable } \\
\text { Tensile } \\
\text { Stress }\end{array}$ & $\begin{array}{c}\text { Allowable } \\
\text { Compressive } \\
\text { Stress }\end{array}$ \\
\cline { 2 - 7 } & $\sigma_{\mathrm{T}}$ (Mpa) & $\sigma_{\mathrm{C}}$ (Mpa) & $\sigma_{\mathrm{T}}$ (Mpa) & $\sigma_{\mathrm{C}}$ (Mpa) & $\sigma_{\mathrm{T}}$ (Mpa) & $\sigma_{\mathrm{C}}$ (Mpa) \\
\hline Ground D151 & 26 & 259 & 36 & 359 & 47 & 473 \\
\hline Ground D64 & 27 & 265 & 27 & 265 & 35 & 351 \\
\hline Ground D64 Etched Std 73 & 79 & 785 & 106 & 1064 & 139 & 1385 \\
\hline
\end{tabular}

Table 7. KPF Zerodur allowable stress 


\subsection{Hertzian Contact Stress Calculation}

Hertzian stress between the two shims was calculated using equations in Timoshenko and Goodier $(1951)^{7}$ (shown in Figure 25). These peak shim cases are tracked through a spreadsheet that calculates the hertzian stress for each optic given its CG height, shim spacing, shim orientation, and max acceleration as shown in Table 8. Finite element analysis was employed to verify these results.

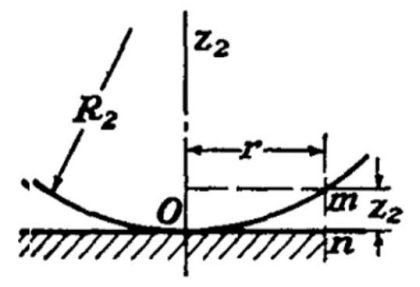

$$
\begin{aligned}
& k_{1}=\frac{1-v_{1}^{2}}{\pi E_{1}}, k_{2}=\frac{1-v_{2}^{2}}{\pi E_{2}} \quad \text { Timoshenko pg } 374, \text { eq } 216 \\
& E_{C}=k_{1}+k_{2} \\
& \beta=\frac{1}{2 R_{2}} \text { Timoshenko, pg } 373 \text {, eq. c, Sphere on Plane } \\
& q_{0}=\frac{3 P}{2 \pi a^{2}} \text { Timoshenko, pg } 375 \text {, eq. } 218 \\
& a=\frac{E_{C} \pi^{2} q_{0}}{4 \beta} \text { Timoshenko, pg } 375 \text {, eq. } 217 \\
& \text { Combine above: } \quad q_{0}=\left[\frac{48 P \beta^{2}}{2 \pi^{5} E_{C}^{2}}\right]^{\frac{1}{3}}=\text { Max Compressive Stress } \\
& \vartheta_{t}=\vartheta_{r}=\frac{(1-2 v)}{3} q_{0}=\text { Max Tensile Stress, Timoshenko, pg. } 376
\end{aligned}
$$

\begin{tabular}{|c|c|c|c|c|c|c|c|c|}
\hline \multirow{5}{*}{ Hertzian Stress Summary } & \multirow{5}{*}{$\begin{array}{l}\text { Max } \\
\text { Tensile } \\
\text { Stress, } \\
\text { Short } \\
\text { Duration } \\
\text { (Mpa) }\end{array}$} & \multirow{5}{*}{$\begin{array}{c}\text { Max } \\
\text { Tensile } \\
\text { Stress, } \\
\text { Long } \\
\text { Duration } \\
\text { (Mpa) }\end{array}$} & \multirow{5}{*}{\begin{tabular}{|c|} 
Allowable \\
Tensile \\
Stress, \\
Short \\
Duration \\
(Mpa)
\end{tabular}} & \multirow{5}{*}{$\begin{array}{c}\text { Allowable } \\
\text { Tensile } \\
\text { Stress, } \\
\text { Long } \\
\text { Duration } \\
\text { (Mpa) }\end{array}$} & \multirow{5}{*}{$\begin{array}{c}\text { Factor of } \\
\text { Safety, Short } \\
\text { Duration }\end{array}$} & \multirow{5}{*}{\begin{tabular}{|c|} 
Factor of \\
Safety, Long \\
Duration
\end{tabular}} & $\operatorname{Gravity}\left(\mathrm{m} / \mathrm{s}^{2}\right):$ & 9.810 \\
\hline & & & & & & & Vibration Acceleration (G): & 0.92 \\
\hline & & & & & & & Gusset? & 0 \\
\hline & & & & & & & Spring F.S.: & 1.000 \\
\hline & & & & & & & Flat Elastic Modulus, $\mathrm{E}_{\mathrm{F}}(\mathrm{Gpa}):$ & 90.3 \\
\hline Reformatter & 13 & 9 & 139 & 79 & 10.5 & 8.4 & Flat Poisson Ratio, $v_{\mathrm{F}}$ : & 0.24 \\
\hline Primary Collimator & 17 & 12 & 139 & 79 & 8.1 & 6.4 & $K_{F}(1 / P a):$ & $3.32 \mathrm{E}-12$ \\
\hline Echelle & 11 & 11 & 139 & 79 & 13.2 & 7.5 & Sphere Elastic Modulus, $E_{s}(G p a):$ & 90.3 \\
\hline Echelle Assembly & 14 & 12 & 139 & 79 & 10.0 & 6.4 & Sphere Poisson Ratio, $v_{s}:$ & 0.24 \\
\hline Fold Mirror & 8 & 6 & 139 & 79 & 16.8 & 13.2 & Sphere Diameter $(m):$ & 2 \\
\hline Secondary Collimator & 15 & 11 & 139 & 79 & 9.4 & 7.4 & $\mathrm{~K}_{\mathrm{S}}(1 / \mathrm{Pa}):$ & $3.32 \mathrm{E}-12$ \\
\hline Dichroic & 9 & 6 & 139 & 79 & 16.1 & $\begin{array}{c}12.3 \\
8.1\end{array}$ & $E_{c}(1 / \mathrm{Pa}):$ & $6.64 \mathrm{E}-12$ \\
\hline $\begin{array}{r}\text { Red Fold Mirror } \\
\text { Camera }\end{array}$ & $\begin{array}{l}13 \\
15\end{array}$ & $\begin{array}{l}10 \\
13\end{array}$ & $\begin{array}{l}139 \\
139\end{array}$ & $\begin{array}{l}79 \\
79\end{array}$ & $\begin{array}{c}10.6 \\
9.2\end{array}$ & $\begin{array}{l}8.1 \\
6.2\end{array}$ & $\begin{aligned} & E_{c}(1 / P a) 0 \\
& \beta(1 / m):\end{aligned}$ & 0.50 \\
\hline
\end{tabular}

Figure 25. Hertzian stress equations (from Timoshenko and Goodier, 1951 ${ }^{7}$ )

Table 8. Summary of hertzian stress and factors of safety for shims

\subsection{Shim Testing}

During the preliminary design phase we purchased 24 shims (12 spherical, 12 flat) for testing. The shims have undergone four types of testing to date: cyclic loading; flat on flat loading; sphere on flat failure failure loading; and assembly impact testing.

The first test cycled a shim stack pair fifty times to twice our max expected mounting force of 250 lbs to simulate multiple mount and dismount cycles. During the alignment phase, we expect to mount and dismount the optics approximately 10 times; therefore, this test applies twice the load at five times the expected number of cycles.

The second test took this same shim stack and loaded it to 20,000 lbs in a reverse orientation so the shims contacted flat to flat instead of sphere to flat. As can be seen in the test fixture shown in Figure 26, PEEK washers are used to remove the relevance of the top and bottom fixture surfaces from the test. Since PEEK is compliant at these loads, it uniformly applies the load and restrains the shim set. The intention of reversing the shim stack was to investigate the flat-on-flat shim-optic and shim-bench interfaces. This test was not done to failure, but to 40 times our maximum expected shim loads under the earthquake survival accelerations. The shims survived this testing with no noticeable effects.

The third test took the same shim stack from the second test and two additional shim pairs and tested them to failure in a 24 ton hydraulic press with the normal sphere to flat interface. These three results are too small a sample to draw statistical results from, but they do serve as a "gut check" of our failure load expectations. The earliest shim failure occurred at 12,000 lbs, which is 25 times our worst expected load. The summary for these first three tests is shown in Table 9. 


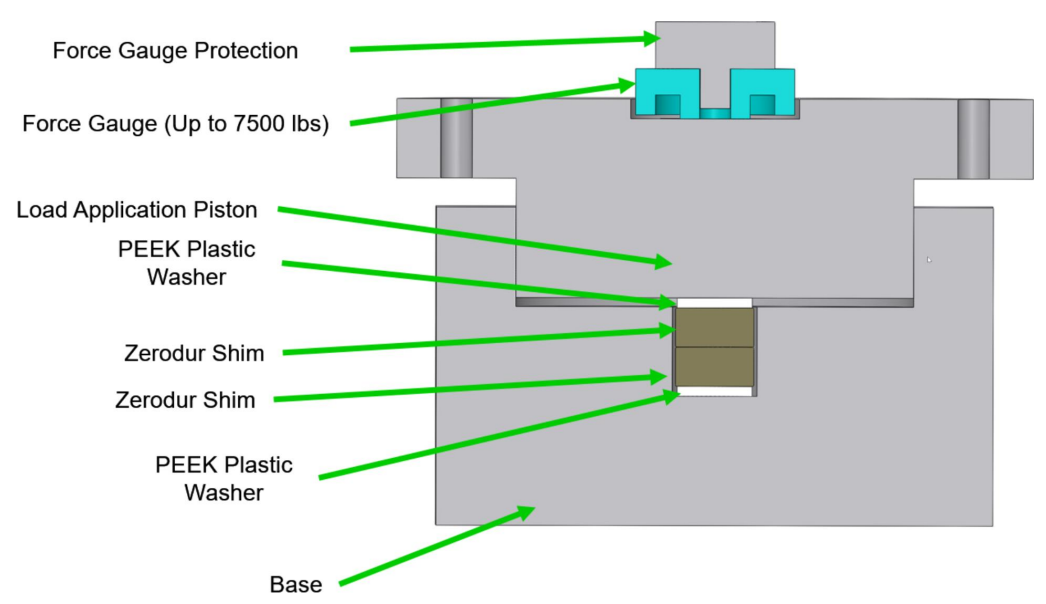

Figure 26. Shim testing fixture

\begin{tabular}{|c|c|c|c|c|c|}
\hline \multicolumn{6}{|c|}{ Shim Load Testing Summary } \\
\hline \multicolumn{2}{|c|}{ Shim Serial Numbers } & \multirow{2}{*}{ Cycle Test } & \multirow{2}{*}{$\begin{array}{c}\text { Flat on Flat } \\
\text { Test } \\
\text { (lbs) }\end{array}$} & \multicolumn{2}{|c|}{ Flat on Sphere Failure Test } \\
\hline KPF-SPE-MEC-111 & KPF-SPE-MEC-112 & & & $\begin{array}{l}\text { Failure Load } \\
\text { (lbs) }\end{array}$ & $\begin{array}{l}\text { FS in Load at } \\
\text { Failure }\end{array}$ \\
\hline 4 & 5 & $\begin{array}{c}50 \text { Cycles, } \\
500 \text { Lbs }\end{array}$ & 20,000 & 30,000 & 62 \\
\hline 12 & 7 & - & - & 12,000 & 25 \\
\hline 11 & 6 & - & - & 20,000 & 41 \\
\hline
\end{tabular}

Table 9. Shim load testing summary

In the fourth test we put a full set of shims into an aluminum example of the red fold mirror bench pocket. We then mounted an aluminum version of the red fold mirror ten times into the pocket using our optic lift fixture, a crane, and a Hydra Set. This test is meant to duplicate the shim impact loads as we load optics onto the bench, Figure 27. These shims survived this testing and showed no signs of damage when examined under a microscope.

\subsection{Engineering Test Units for Optical Mounts}

To test the KPF optic mounting scheme, two engineering test unit (ETU) versions of the red fold mirror mount were built, one in aluminum and one in Zerodur.

The aluminum ETU consists of an aluminum base block with a machined pocket to replicate the pocket in the KPF spectrometer bench, and an aluminum duplicate of the red fold mirror as shown in Figure 27. It uses a full set of Zerodur shims and the ETU Type I horizontal and vertical spring sets.

The Zerodur ETU is mechanically identical to the aluminum ETU, except for material. It is important to note that the Zerodur ETU mirror is actually the substrate of the red fold mirror that will ultimately be integrated into the KPF spectrometer. For this reason, the aluminum ETU was fabricated to proof the optic integration steps and perform a mass model survival vibration, to reduce any risk of damaging the Zerodur ETU mirror. The following tests have been devised to validate the KPF optic mounting scheme:

- Repeated optic integration into bench pockets - Aluminum ETU. (Complete);

- Absolute alignment and alignment repeatability in air - Aluminum ETU (Complete);

- Vibration to earthquake survival loads - Aluminum ETU (Complete), Zerodur ETU (Not yet completed);

- Alignment stability in vacuum - Zerodur ETU (In Process). 


\subsubsection{Aluminum Red Fold Mirror ETU Tests}

Two tests were completed with the aluminum ETU. The first test consisted of repeatedly installing the red fold into the aluminum base block, and measuring its alignment after each installation using a laser tracker. This was done using the same optic lift fixture, overhead crane, and precision load positioner that will be used during the KPF spectrometer integration at SSL. This test verified the optic integration approach, shim mounting loads, and alignment repeatability in air. Additionally, the Zerodur shims were exchanged to establish absolute alignment in air (i.e., different shim dimensions were used to invoke mirror tip/tilt to optimize alignment). The test setup is shown in Figure 27. Repeatability between remounts was demonstrated to i 5 arcseconds and the shim exchanges were predictable.

Disassembled Aluminum ETU

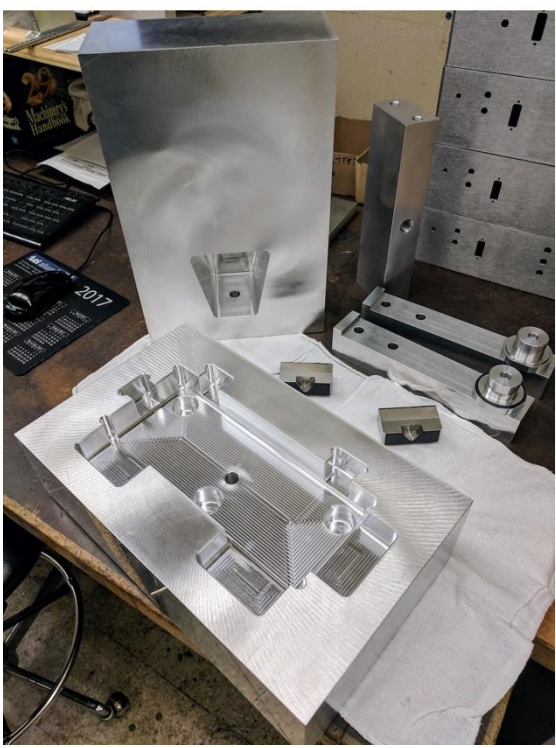

Alignment Repeatability and Shim Impact Test

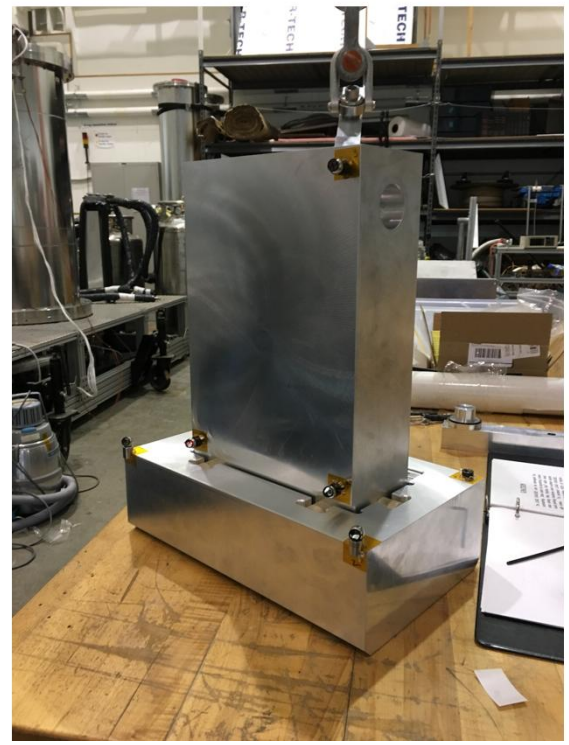

Survival Vibration Testing

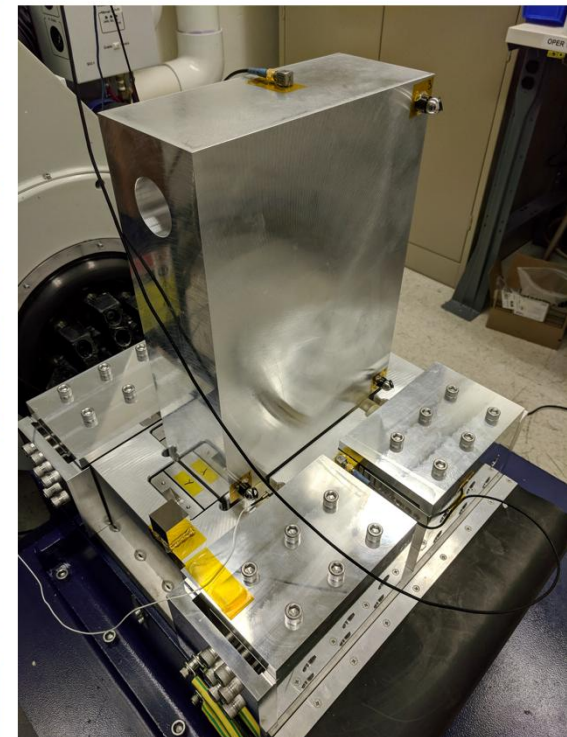

Figure 27. Disassembled aluminum ETU (left), ETU alignment repeatability and shim impact test configuration (center). Vibration test setup (right). Spherically mounted retro-reflectors were mounted to the aluminum ETU mirror and base to track relative alignment.

The second test was the vibration of the entire assembly to earthquake survival loads. This test took place on the vibration table at SSL. The ETU was clamped to the vibration table as shown in Figure 27 and subjected to random vibration consistent with the specified survival earthquake loads (Section 4.2.1). This test is intended as a trial run for the Zerodur ETU and was a way to get early results of the mounting system before PDR. Laser tracker alignment checks before and after the $0.6 \mathrm{~g}$ test varied by 9 arcseconds, well under the tightest alignment tolerance requirement of 31 arcseconds.

\subsubsection{Zerodur Red Fold Mirror ETU Tests}

Following the successful test campaign with the aluminum ETU assembly, we have started the Zerodur ETU tests. It is currently undergoing alignment stability tests under induced thermal gradients within a vacuum chamber. Following this it will undergo survival vibration testing.

For the thermal gradient test, the Zerodur ETU has four towers clamped to the Zerodur base block. These towers contain grooves for mounting six SmarAct laser distance interferometers. These units provide distance measurements to sub-nanometer precision. ${ }^{8}$ Three of the SmarActs reflect off of the front surface of the red fold mirror and another three reflect off two of the towers. The reflective surfaces of the red fold and reference mirrors are coated with aluminum. A differential measurement will be made at each of the three locations to determine angular tip/tilt of the fold mirror relative to the base plate. A heater is bonded to the back side of the mirror, to induce a thermal gradient through the thickness of the mirror and therefore induce bending of the optic in the pitch direction. The test setup prior to loading into the thermal vacuum chamber is shown in Figure 28. 


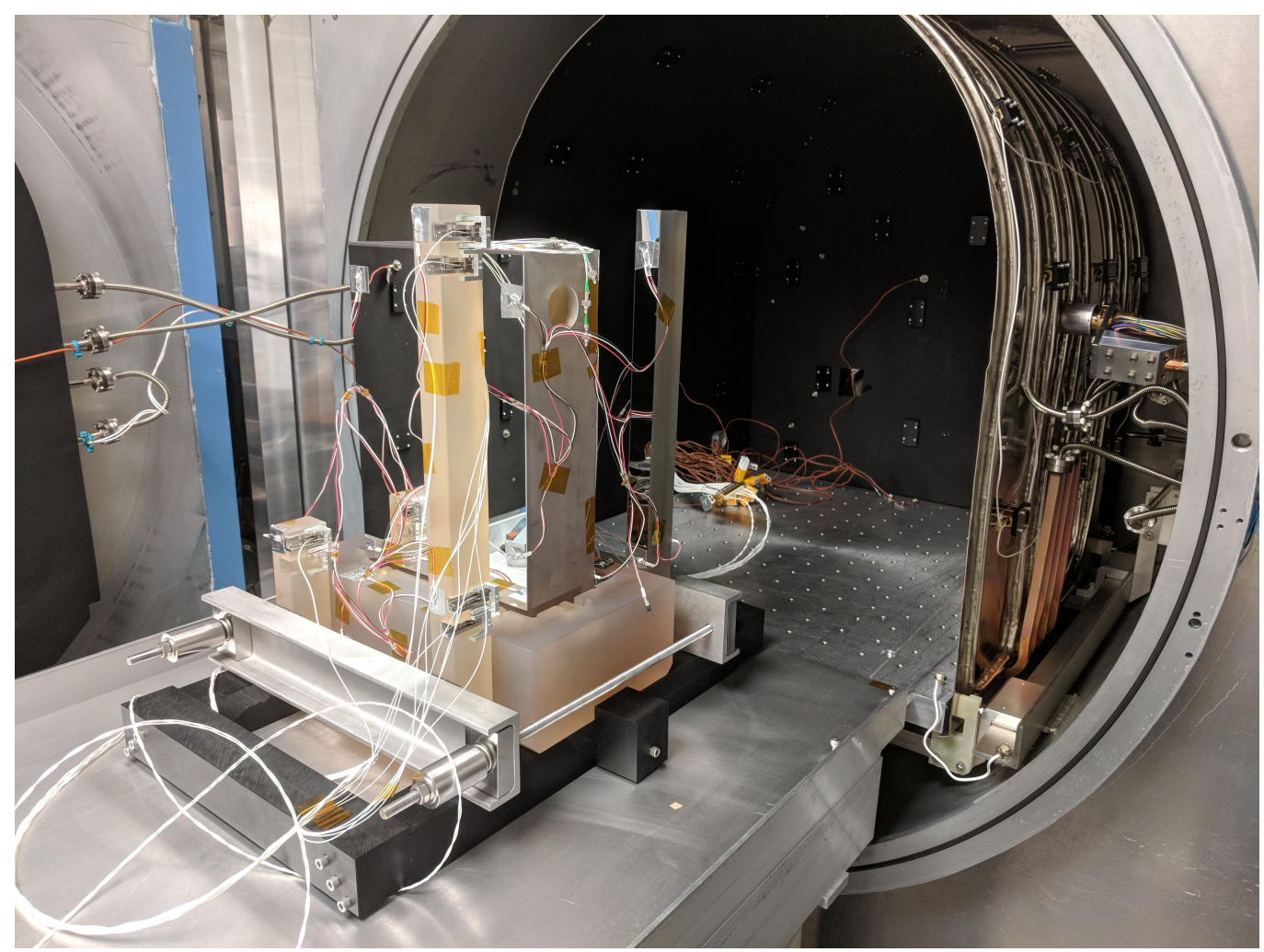

Figure 28. Zerodur ETU stability test setup before loading into thermal vacuum chamber with 6 laser distance interferometers to track mirror tip and tilt. Note a second smaller tower is hidden behind the mirror in this view.

\section{ACKNOWLEDGMENTS}

The authors thank the Heising-Simons Foundation; the W.M. Keck Foundation; the University of California, Berkeley; the California Institute of Technology; and the University of Hawaii for financial support of KPF. The authors also wish to thank Winlight Systems for their valuable contributions to the designs of the reformatter and cameras, as well as the DESI project for sharing both their camera designs and their expertise with optical fibers.

\section{REFERENCES}

[1] Gibson, S. R. et al., "Keck Planet Finder: Preliminary Design," in [Ground-based and Airborne Instrumentation for Astronomy VI], Proc. SPIE 10702 (Aug. 2018).

[2] Gibson, S. R., "Tolerancing a radial velocity spectrometer within Zemax," in [Modeling, Systems Engineering, and Project Management for Astronomy VI], Proc. SPIE 9911, 99112C (Aug. 2016).

[3] Westerhoff, T., Davis, M., Hartmann, P., Hull, T., and Jedamzik, R., "Lightweighted ZERODUR for telescopes," in [Advances in Optical and Mechanical Technologies for Telescopes and Instrumentation], Proc. SPIE 9151, 91510R (July 2014).

[4] Paquin, R. A., "Materials for optical systems," in [Handbook of Optomechanical Engineering], Ahmad, A., ed., CRC Press (1997).

[5] Crouse, C., "Site-specific seismic hazard assesment of proposed Thirty Meter Telescope Site, Mauna Kea, Hawaii," tech. rep., United Research Services Corporation (2010).

[6] Schott, "Bending strength of optical glass and zerodur, TIE-33," tech. rep., Schott Advanced Optics (2015).

[7] Timoshenko, S. and Goodier, J. N., [Theory of Elasticity], McGraw-Hill Book Company (1951).

[8] SmarAct, "Position, stability, and resolution of a picoscale interferometer," tech. rep., SmarAct GmbH (2017). 